UNIVERSIDAD NACIONAL DEL NORDESTE

FACULTAD DE CIENCIAS AGRARIAS

CORRIENTES, REṔ BLICA ARGRNTINA

B O N P L A N D I A

Tomo III

Febrero de 1977

$\mathrm{N}^{\mathrm{O}} 15$

\title{
VENACION FOLIAR MENOR EN BYTTNERIA (STERCULIACEAE)
}

Por MARIA M. ARBO (1)

El sistema vascular de las hojas de Angiospermas ofrece dos niveles de organización que se denominan venación mayor y menor. La venación mayor comprende las venas que parten del pecíolo y las que derivan directamente de ellas, en tanto que la venación menor es el conjunto de las venas más delgadas y vénulas cuando las hay.

Varios autores intentaron poner un límite entre venación mayor y menor, basándose algunos en el orden de vena, otros en la estructura anatómica de las mismas. Así Plymale y Wylie (1944) establecieron que venas mayores son las que tienen crecimiento secundario y poseen vasos y tubos cribosos, en tanto que venas menores son las que poseen sólo traqueidas y parénquima floemático y no tienen crecimiento secundario. Los trabajos de autores posteriores probaron la inutilidad de pretender una clasificación rígida; ya que la variación morfológica -de las hojas es infinita y depende no sólo de factores genéticos sino ambientales y fisiológicos (Hanson, 1917; Ryder, 1951).

En términos generales podría decirse que venación mayor es la

(1) Facultad de Ciencias Agrarias, UNNE, Corrientes. Miembro de la Carrera del Investigador Científico y Tecnológico del CONICET, organismo que financió la publicación de este trabajo. 
que se puede describir macroscópicamente, y venación menor es aquella que se observa con el auxilio del microscopio.

Hay numerosos trabajos publicados sobre venación foliar menor de Dicotil dóneas, pero generalmente se trataron especies aisladas o se hicieron estudios de tipo fisiológico o en relación con las condiciones ecológicas. Sólo unos pocos trabajos abarcan un cierto número de especies de una familia o género.

No encontré antecedentes sobre venación monor' de Byttneria ni de otros géneros de Sterculiaceae, aunque hay algunos trabajos que versan sobre aspectos relacionados.

A pesar de los numerosos trabajos publicados, el conocimiento de la venación menor de hojas de dicotiledóneas es aún incipiente. Se han propuesto varios criterios para clasificarla y se han establecido categorías para determinados elementos como las vénulas, pero hasta el momento ninguno es satisfactorio porque continuamente se descubren nuevos modelos.

Wylie (1939) y Philpott (1953) describen la venación menor utilizando como índice el intervalo intervascular, y lá presencia y frecuencia de extensiones de la vaina. Según estos autores la proximidad y distribución de venas con extensiones de la vaina influencian notablemente la disposición de las venas menores.

Kapoor, Sharma y col. (1969) estudiaron la venación menor en especies de Apocynaceae estableciendo la superficie de las aréolas y el número de las mismas y de vénulas por $\mathrm{cm}^{2}$. No consideraron la estructura de las vénulas ni la presencia de vaina o extensiones.

El método de Hickey (1973) para el estudio de la venación es la determinación del orden de cada vena, sobre la base de su tamaño relativo en su punto de origen. Se considera el comportamiento de la vena en relación con venas de otros órdenes y con rasgos marginales de la hoja. Este sistema resulta sumamente complicado para el estudio de la venación menor, pues el máximo orden de vena que presenta una hoja determinada parece estar relacionado con el tamaño de la lámina, y en cierta medida con su forma. Además, en numerosas especies, las hojas presentan formas y tamaños diferentes desde la base al ápice de la misma planta. Por otra parte, Hickey no 
considera en su análisis, por estar destinado especialmente a los paleobotánicos, la presencia de vaina y extensiones, la estructura de las mismas y de las venas, que confieren un aspecto particular a la venación de las distintas especies.

El presente trabajo es el estudio de la venación foliar menor de las hojas del género Byttneria. Analicé nomófilos adultos de 119 de las 131 especies del género, considerando todos los elementos que intervienen en la venación menor. Para la clasificación tomé en cuenta los caracteres más constantes a nivel específico.

Al analizar la venación menor de la cassi totalidad de especies del género, pude observar la amplitud de variación de la misma, así como su relación con otros caracteres.

La venación mayor de Byttneria presenta gran diversidad: en las distintas especies aparecen los tipos craspedódromo, camptódromo y broquidódromo (Hickey, 1973). Como la venación mayor parece no estar correlacionada con la venación menor, no la estudié en forma sistemática.

\section{Antecedentes bibliográficos}

El estudio de la venación foliar de Angiospermas se ha desarrollado recién en las últimas cuatro décadas, aunque hay algunos trabajos clásicos que datan del siglo XIX.

Entre 1856 y 1865 aparecieron los trabajos de Ettingshausen, quien propuso la terminología usada hasta la actualidad para designar los tipos de venación mayor. Los autores que posteriormente trataron el tema, como Kerner y Oliver (1895) y Hickey (1973) usaron los vocablos propuestos por Ettingshausen con igual o similar acepción.

La venación menor no se estudió como tal hasta la década del 30 , pero anteriormente se publicaron numerosos trabajos relativos a anatomía, fisiología o ecología, donde se encuentran datos muy importantes sobre los elementos estructurales que componen la venación menor: vénulas, vaina fascicular, extensiones de la vaina, aréolas, etc.

En muchos trabajos se plantea la posible relación entre el hábitat 
y la esclerosis foliar, considerada como un carácter xeromorfo por su frecuente aparición en plantas xerófilas. También se ha estudiado la función de la vaina fascicular y su relación con el tejido de transfusión de las gimnospermas.

\section{Resumen histórico}

En 1879 De Vries describió las vainas que rodean las venas menores de las hojas de remolacha y observó que forman un sistema interconectado (Armacost, 1944: 157).

En 1882 Haberlandt reconoció la presencia de una vaina amilífera en hojas de dicotiledóneas, atribuyéndole funciones de conducción (Armacost. 1944: 158).

En 1885 Fischer estudió las vénulas clasificándolas en dos tipos: principales (vénulas ramificadas que poseen floema con elementos enucleados) y secundarias (vénulas cortas, a menudo formadas por una sola traqueida, desprovistas de floema) (Pray, 1954: 663).

En 1886 Heinricher observó a lo largo de los haces vasculares de las hojas de cuatro especies de dicotiledóneas unas células que denominó traqueidas de almacenamiento de agua (Takeda, 1913: 361).

En 1897 Schubert reconoció 2 clases de vainas amilíferas, una con parénquima neural asociado y otra sin él. Corresponden a las vainas con y sin extensiones respectivamente. Schubert sugirió la posibilidad de que el parénquima participe en el trasporte de sustancias asimiladas (Armacost, 1944: 157).

Takeda (1913) comparó las traqueidas de acumulación que aparecen en las hojas de dicotiledóneas con el tejido de transfusión de las coníferas, atribuyéndoles a ambos funciones de reserva de agua.

En 1931, Pirwitz estudió las "traqueidas de acumulación" en hojas de algunas dicotiledóneas indicando que cumplen la función de facilitar al mesófilo la extracción de agua desde los elementos de conducción. Son elementos terminales muy agrandados y de forma irregular.

Strain en 1933 clasificó las vénulas de las hojas en cinco categorías según el número de elementos traqueales que componen las mismas, estableciendo que no encontró relación entre dichas categorías 
y las divisiones taxonómicas.

Yarbrough en 1934 hizo un estudio ontogenético de la hoja en Bryophyllum, describiendo la venación de la hoja adulta. Las venas menores delimitan "isletas" triangulares o cuadrangulares carentes de vénulas.

Dehay en 1939 estudió los hacecillos de conducción de pecíolo y base de lámina foliar de numerosas Sterculiaceae entre las cuales observó dos especies de Byttneria.

Wylie publicó entre 1938 y 1946 una serie de trabajos importantes. Estudió numerosas especies, seleccionándolas sobre la base de su hábitat o forma biológica. Según este autor las vainas de las venas menores participan en la conducción de agua y solutos. Estableció además que la organización del mesófilo está relacionada con la distribución de las venas: cuanto mayor es la cantidad de tejidos paradermales (esponjoso y epidermis), las venas están más distanciadas.

Armacost (1944) publicó un trabajo detallado sobre la vaina parenquimática de los hacecillos foliares ("border parenchyma") y extensiones de la vaina ("vein ribs"). Demostró experimentalmente que estas estructuras parenquimáticas transportan material de las venas a la epidermis. Según este autor la vaina formaría parte funcionalmente del sistema vascular, a pesar de su similitud morfológica con el mesófilo. Armacost sugirió que la vaina sea considerada como un "órgano" de la hoja, indicando que posiblemente tenga especializaciones tan distintas como las venas, epidermis y mesófilo.

Eames y Mac Daniels (1947) interpretan que las capas de esclerénquima foliar previenen la pérdida de agua y pueden actuar como un filtro parcial contra la luz intensa.

Según Shields (1950) los factores del medio pueden condicionar la aparición de caracteres xeromorfos en hojas normalmente mesomorfas.

Metcalfe y Chalk (1950) describen, entre los caracteres foliares que pueden tener valor taxonómico: 1) las venas "vertically transcurrent" (con extensiones de la vaina) que son frecuentes, dentro del orden Malvales, en la familia Malvaceae; 2) venas rodeadas por una vaina parenquimática, que no se mencionan para las Malvales. 
Foster publicó, entre 1950 y 1952, varios trabajos sobre venación en distintas especies, ocupándose especialmente de su ontogenia. En 1966 estudió la venación de Circaeaster discutiendo su significación evolutiva.

Wylie (1951) analizó los caracteres estructurales y el volumen en hojas de la periferia y del interior de la copa de 10 especies leñosas de dicotiledóneas, observando diferencias según la localización de las hojas y las estaciones·del año. En 1952 estudió las extensiones de la vaina de los hacecillos foliares en 348 especies, destacando las variaciones de esta estructura. Señala que hay mayor frecuencia de extensiones en hojas delgadas deciduas y menor frecuencia en hojas amplias persistentes. En 1954 estudió un grupo de especies leñosas de Nueva Zelandia; halló que carecen de extensiones de la vaina presentando en cambio caracteres xeromorfos.

Philpott, en 1953, realizó un estudio sobre 47 especies de Ficus (un $10 \%$ del género). Estableció 5 tipos de venación menor en base a la frecuencia de venas con extensiones de la vaina, forma de las aréolas y número y tipo de vénulas. Coincide con Wylie en que las especies de mayor densidad de venación poseen mayor cantidad de parénquima èn empalizada.

En 1956 Philpott estudió la organización foliar de un grupo de especies arbustivas utilizando para clasificar la venación menor los mismos criterios que en el trabajo anterior. Denomina como "transcurrent" a las venas con extensiones de la vaina y "embedded" a las venas provistas solamente de vaina.

En 1954-55 se publicaron' los interesantes trabajos de Pray sobre venación foliar de Liriodendron y Hosta. Pray destacó que la división de venas en mayores y menores se establece meramente por conveniencia; definió la venación menor como el retículo formado por las venas últimas y las vénulas.

En los años subsiguientes aparecieron numerosos trabajos sobre venación foliar, con frecuencia estudiada en relación con la ontogenia, destacándose los estudios de Carlquist (1957-59). Según comprobó este autor en especies de Mutisieae, las vainas pueden contener fibras o estar formadas sólo de ellas o de esclereidas. 
Arens en 1958 propuso su teoría del escleromorfismo oligotrófico, según la eual es escleromorfismo foliar se debería a ciertos efectos metabólicos.

En Brasil se están publicando, desde hace varios años, estudios de anatomía y venación foliar de plantas del "cerrado" y la "caatinga", con la participación de numerosos autores. Handro (1964 y 1966) halló vainas lignificadas en Gomphrena prostrata y comprobó que su presencia no tiene relación con el balance hídrico ni con la nutrición mineral. Paula (1966) encontró en Compuestas células de la vaina con espesamientos' celulósicos o hemicelulósicos. Morretes (1966) citó vainas esclerificadas para Copaifera langsdorfii; resumiendo las opiniones de otros autores dice que xerofitismo y xeromorfismo no coexisten obligatoriamente, y que los caracteres xeromorfos se pueden encontrar en mesófitos y raramente en higrófitos. Chacur (1968) halló en especies de Anacardiaceae vainas de células lignificadas envolviendo incluso las vénulas.

En 1966 y 1972 se publicaron los trabajos de Mouton sobre la importancia de la morfología foliar en paleobotánica y filogenia. En ellos establece los tipos foliares característicos de distintas familias señalando para las Sterculiaceae hojas simples pinnadas, palmatilobas y compuestas digitadas. La venación mayor puede ser actinódroma palmeada o imperfecta, broquidódroma o camptódroma. Reconoce además que la venación menor raramente se conserva en los fósiles y prácticamente no se toma en cuenta en su descripción.

Napp-Zinn (1973-74) publicó una extensa obra sobre anatomía de hojas angiospérmicas, analizando detalladamente la estructura de los hacecillos de conducción, vainas, extensiones, vénulas, tejidos de sostén, pero sin considerar la disposición espacial de estos elementos en la lámina. Dedica un capítulo al tejido de transfusión, citando los autores que lo mencionan para hojas de angiospermas. Considera dudosa su identidad con el tejido de transfusión de gimnospermas.

En 1974 apareció la revisión de Dilcher sobre medios de identificación de restos foliares, quien analiza, además del tral;ajo de Hickey (1973), otros relacionados con cutícula y especialmente clasificación de estomas. 


\section{Material y métodos}

Utilicé hojas adultas de ejemplares de herbario, que diafanicé siguiendo métodos diversos. Obtuve los mejores resultados con la técnica de Dizeo de Strittmatter (1973).

Hice cortes transversales de lámina de numerosas especies, y en algunos casos utilicé también cortes longitudinales. Coloreé los cortes a mano alzada con carmín bórico-verde de yodo (Scala, 1908) y los cortes con micrótomo con safranina-fast green.

Estudié los preparados con ayuda de un microscopio Wild M-20; el empleo de luz polarizada me resultó de gran utilidad para observar la distribución del esclerénquima foliar y de los cristales.

Para comparar la venación menor de las especies dibujé esquemáticamente, con cámara clara, una superficie equiparable de hoja diafanizada, evitando la vena primaria.

\section{Descripción general de la venación menor de Byttneria}

Los caracteres que tomé en cuenta para describir la venación menor fueron: forma de las aréolas; frecuencia, número, ramificación y composición de las vénulas; estructura de la vaina fascicular; composición y topografía del esclerénquima foliar; presencia de extensiones de la vaina; ocurrencia y tipo de cristales.

La venación menor en Byttneria presenta aréolas bien delimitadas, de forma y tamaño variables, dispuestas de manera irregular, sin o con vénulas simples (lineares o curvadas) o ramificadas (una, dos o más veces) (Hickey, 1973).

Las venas están compuestas por hacecillos colaterales. Generalmente las vénulas están constituídas por traqueidas espiraladas y a veces escalariformes o punteadas (Lám. 5, E-I).

Todas las venas y aún las vénulas están rodeadas por una vaina. En la mayor parte de las especies la vaina es parenquimática; en otras hay una vaina diferenciada; formada por células especializadas, de paredes gruesas, a menudo lignificadas, provistas de puntuaciones 
simples notables o con puntuación escalariforme. Son elementos cortos o poco alargados, cuyos extremos se superponen y a veces presentan bracitos muy cortos o prominencias que se proyectan hacia el mesófilo. En ciertos casos, las últimas venas y las vénulas están constituídas solamente por células de la vaina. Las especies restantes poseen vaina intermedia, con elementos especializados en las venas mayores y parenquimáticos al final (Lám. 5, A-C).

Todas las especies de Byttneria presentan extensiones de la vaina en las venas mayores; muchas especies las presentan también en las venas menores, aunque generalmente faltan en las últimas venas. Las vénulas no presentan extensiones. La densidad y tipo de venación parecen no estar determinados por la frecuencia de extensiones, ya que hay especies que difieren en este aspecto y sin embargo se asemejan en todos los demás elementos de la venación menor.

La cantidad de tejido esclerenquimático presente en la hoja ofrece amplia variabilidad. Los elementos esclerenquimáticos se encuentran fundamentalmente acompañando las venas; cuando menor es la cantidad de estos elementos, se los encuentra junto a venas de mayor grosor. Como la densidad de esclerénquima resultó un carácter práctico para agrupar las especies, establecí 4 categorías que denomino de la siguiente manera: esclerénquima mononeural: acompaña solamente la o las venas primarias; esclerénquima oligoneural: acompaña también venas generalmente gruesas que rodean grupos de aréolas; esclerénquima polineural: las células esclerenquimáticas acompañan hasta las venas que delimitan las aréolas; esclerénquima holoneural: los elementos esclerenquimáticos acompañan incluso las vénulas y aún en muchas especies hay brazos que atraviesan el mesófilo. En las especies cuyas vénulas presentan elementos punteados, muchas veces es problemática la distinción entre estas células y las esclerenquimáticas.

En las especies de esclerénquima mononeural, los elementos esclerenquimáticos son fibras típicas, en tanto que las especies de esclerénquima holoneural presentan verdaderas esclereidas, de formas y tamaños diversos. Los casos intermedios ofrecen toda la escala de variación, haciendo imposible poner un límite neto entre fibras y es- 
clereidas. Por esta razón, considero que para denominar estas células, el término más adecuado es el de fibroesclereidas (Esau,1965:204).

Por otra parte, en algunas de las especies que poseen vaina con células de paredes gruesas y lignificadas, también se vuelve difícil la distinción entre estos elementos y los que constituyen el esclerénquima.

La presencia de cristales es un rasgo muy frecuente en el género, son muy' pocas las especies que carecen de ellos. Pueden ser prismáticos de tamaño variable o drusas, y generalmente se los halla acompañando las venas, contenidos en células de la vaina, o de las extensíones de la vaina. Algunas especies los presentan también en el mesófilo. Sin embargo, la presencia de cristales no es un carácter específico constante, pues hay especímenes que los poseen y otros que no. También varían la forma de los cristales y su densidad en los distintos ejemplares. Muchas veces no aparecen en la hoja diafanizada, mientras se observan muy bien en cortes de lámina del mismo ejemplar. Cabe la posibilidad de que en la hoja diafanizada se hayan disuelto por la acción de alguno de los reactivos empleados.

\section{Tipos de venación menor en Byttneria}

En Byttneria aparecen dos tipos básicos de venación menor. Los caracteres que resultaron útiles para separarlos fueron: la forma de las aréolas y la frecuencia y clase de vénulas.

Para facilitar la descripción agrupé las especies dentro de cada tipo de venación, teniendo en cuenta la naturaleza de la vaina fascicular y la densidad del esclerénquima foliar. Deseo destacar que la variabilidad de los caracteres usados es continua; pude comprobar ésto especialmente cuando dispuse de varios ejemplares de cada especie. Por esta razón, las categorías establecidas no pretenden tener valor absoluto.

Los grupos resultantes, que enumero de 1 a 8, figuran en el cuadro 1. Sobre la ordenada se indican los tipos de venación: anisodictia e isodictia, y sobre la abscisa, la densidad de elementos esclerenquimáticos. Los tipos de vaina fascicular, indicados también sobre la 


\begin{tabular}{|c|c|c|c|c|c|}
\hline \multirow[b]{2}{*}{ 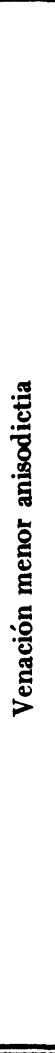 } & 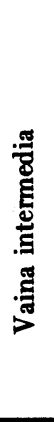 & \multicolumn{2}{|c|}{$\begin{array}{l}\text { SECCIONES } \\
\text { GERONTOGAEA } \\
\text { vahihara } \\
\text { byttneria } \\
\text { crassipetala } \\
\text { URTICIFOLIA } \\
\text { INCASICA } \\
\text { Obs.: el tipo de letra de las especies } \\
\text { indica la sección correspondiente. }\end{array}$} & $\begin{array}{l}\text { catalpaefolia } \\
\text { cordifolia } \\
\text { Gayana } \\
\text { Humbertiana } \\
\text { Idroboi } \\
\text { ovatifolia } \\
\text { ancistrodonta } \\
\text { Aristeguietae } \\
\text { dahomensis } \\
\text { divaricata } \\
\text { LOPEZ-MIRANDAE } \\
\text { WEBERBAUERI } \\
\qquad 3 \mathrm{aa} \\
\end{array}$ & $\begin{array}{l}\text { besalampensis } \\
\text { hirta } \\
\text { lobata } \\
\text { lucida } \\
\text { nitidula } \\
\text { CORIACEA } \\
\text { RHAMNIFOLIA } \\
\text { UROSEPALA } \\
\text { Asplundii } \\
\text { australis } \\
\text { melantha } \\
\text { OBTUSATA } \\
\qquad 4 \mathrm{a} \\
\end{array}$ \\
\hline & \multirow[t]{2}{*}{ 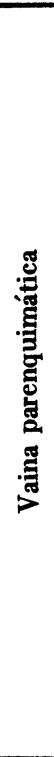 } & $\begin{array}{l}\text { GRACILIPES } \\
\text { MINYTRICHA } \\
\text { TUCUMANENSIS } \\
\text { atrata } \\
\text { Beyrichiana }\end{array}$ & $\begin{array}{l}\text { HERBACEA } \\
\text { elegans } \\
\text { integrifolia } \\
\text { oligantha } \\
\text { pilosa } \\
\text { CELTOIDES } \\
\text { OSTENII } \\
\text { URTICIFOLIA } \\
\text { aculeata } \\
\text { aurantiaca } \\
\text { Ekmanii } \\
\text { Fernandesii } \\
\text { filipes } \\
\text { guineënsis } \\
\text { microphylla } \\
\text { CORDATA } \\
\text { FLEXUOSA } \\
\text { GLABRESCENS } \\
\text { OVATA } \\
\text { PAREIELORA 2 } \\
\end{array}$ & $\begin{array}{l}\text { angulata } \\
\text { benensis } \\
\text { catalp.ssp.afric. } \\
\text { catalp.ssp.sidaef. } \\
\text { erosa } \\
\text { macrantha } \\
\text { tortilis } \\
\text { ABUTILOIDES } \\
\text { HIRSUTA } \\
\text { ivorensis } \\
\text { loxensis } \\
\text { CORYLIFOLIA } \\
\text { SPARREI } \\
\text { VARGASII }\end{array}$ & 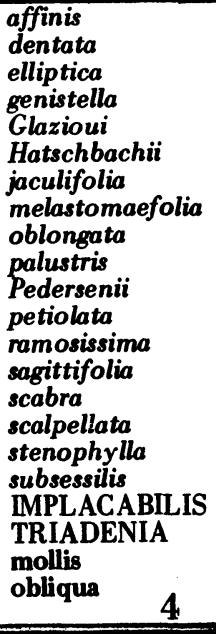 \\
\hline \multirow{3}{*}{ 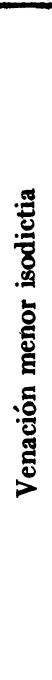 } & & $\begin{array}{l}\text { andamanensis } \\
\text { Bernieri } \\
\text { flaccida } \\
\text { rubriflora }\end{array}$ & $\begin{array}{l}\text { Baronii } \\
\text { oranensis }\end{array}$ & $\begin{array}{l}\text { biloba ssp.Grand. } \\
\text { celebica } \\
\text { nossibeensis }\end{array}$ & \\
\hline & : & & $\begin{array}{l}\text { echinata } \\
\text { heteromorpha }\end{array}$ & \begin{tabular}{|l|}
\multicolumn{2}{|l}{ ambongensis } \\
ambong.ssp.vill. \\
Decaryana \\
heterophylla \\
Perrieri var.Dec. \\
Reinwardtii \\
sambiranensis \\
scabrida \\
vitifolia \\
voulily \\
\end{tabular} & \\
\hline & 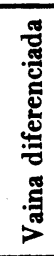 & & \begin{tabular}{|l|} 
crenulata \\
fruticosa \\
grandifolia \\
pescapraeifolia \\
\\
\\
\end{tabular} & $\begin{array}{l}\text { Beccarit } \\
\text { Curtisii } \\
\text { ellipticifolia } \\
\text { fulva } \\
\text { Jackiana } \\
\text { Melleri var.tril. } \\
\text { oblongifolia } \\
\text { uaupensis } \quad 7 \text { b }\end{array}$ & $\begin{array}{l}\text { asterotricha } \\
\text { attenuatifolia } \\
\text { Mastersii } \\
\text { Piresii }\end{array}$ \\
\hline \multicolumn{3}{|c|}{ Esclerénquima mononeural } & oligoneural & polineural & holoneural \\
\hline
\end{tabular}

Cuadro 1: Venación foliar menor de Byttneria. 
ordenada,determinan subgrupos que se distinguen con letras minúsculas.

Las secciones a que pertenecen las especies se indican con distinto tipo de letra.

\section{Venación menor anisodictia $(*)$}

Este tipo de venación se caracteriza por las aréolas de forma y tamaño muy variable en cada hoja, algunas poligonales y otras irregulares que frecuentemente se encuentran en la vecindad de las venas mayores (Pray, 1963: 63). Las aréolas generalmente presentan vénulas que pueden ser simples, rectas o curvas, o diversamente ramificadas. Muchas veces las ramas de las vénulas se anastomosan entre sí delimitando aréolas secundarias dentro de las aréolas (Pray, 1963: 63). En otros casos, especialmente en las aréolas de forma irregular, hay dos o más vénulas, que pueden ser simples o alguna de ellas ramificada.

Algunas de las especies de la sección Vahihara que presentan este tipo de venación, son en cierto modo intermedias, pues poseen menor número de vénulas y éstas son simples o poco ramificadas. Sin embargo las incluí entre las de venación anisodictia por la disposición y forma irregular de las aréolas y la presencia en algunas de ellas de dos vénulas o de aréolas secundarias (Lám. 1).

GRUPO 1. Las especies de este grupo corresponden a las secciones Crassipetala y Urticifolia. Presentan vaina parenquimática y esclerénquima mononeural. Las venas presentan extensiones, exceptuando las que delimitan las aréolas (Lám. 1,A).

El tamaño de las aréolas es variable, en B.gracilipes son muy amplias y en B.atrata reducidas. Están delimitadas por venas de $5^{\circ}$ ó $6^{0}$ orden.

Las vénulas son numerosas, y están constituídas por una o dos filas de traqueidas espiraladas, a veces más en los extremos como en B.minytricha.

(*) Del griego anisos: desigual y diktyon: red. 
GRUPO 2. Comprende especies de las secciones Vahihara, Crassipetala, Incasica, Urticifolia y la única especie de la sección Gerontogaea, B.herbacea. (Lám. 1, B y 4, A-B).

Las especies de este grupo presentan esclerénquima oligoneural y vaina parenquimática. Las aréolas están delimitadas por venas de $5^{\mathbf{O}}$ a $7^{0}$ orden. Algunas especies como B.aculeata y B.flexuosa presentan extensiones solamente en las venas mayores; otras como B.filipes tienen extensiones también en algunas venas de mediano grosor; por último, hay especies como B.herbacea y B.urticifolia que presentan extensiones en todas las venas excepto las que delimitan las aréolas o sea las más delgadas.

El tamaño de las aréolas varía en la hoja y en los distintos especímenes, pero hay especies como B.aurantiaca que presentan generalmente aréolas muy amplias, y otras como B.cordata y B.filipes que poseen aréolas reducidas.

La cantidad de elementos traquealeš que constituye las vénulas varía, en muchas especies como B.celtoides y B.aurantiaca hay solamente 1 ó 2 filas de traqueidas espiraladas; en B.elegans y B.urticifolia aparecen a veces elementos traqueales cortos con paredes gruesas y punteadas. En otras especies como B.ovata y B.filipes las vénulas son robustas, con los extremos constituídos a veces por grupos de tres o más traqueidas espiraladas, y en B.pilosa pueden aparecer también elementos punteados.

Los elementos esclerenquimáticos son largos, delgados, con paredes de espesor variable, bastante gruesas en B.Fernandesii.

GRUPO 3. Las especies de este grupo presentan esclerénquima polineural. Los elementos esclerenquimáticos son largos, delgados, con paredes bastante gruesas, a veces espiculados. Las aréolas se cierran con venillas de $5^{\circ}$ a $7^{\circ}$ orden. Separaré las especies en dos subgrupos: 3 y $3 \mathrm{a}$, según el tipo de vaina que poseen los hacecillos.

SUBGRUPO 3: Vaina parenquimática, en algunas especies con idioblastos que contienen cristales. Algunas especies presentan extensiones sólo en las venas mayores, y otras las poseen en todas las venas excepto las venillas que delimitan las aréolas. Las especies de este 


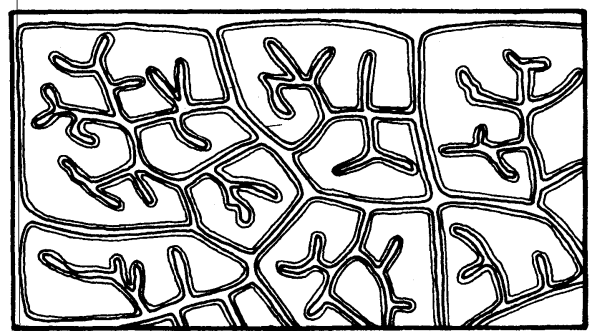

A. Grupo 1

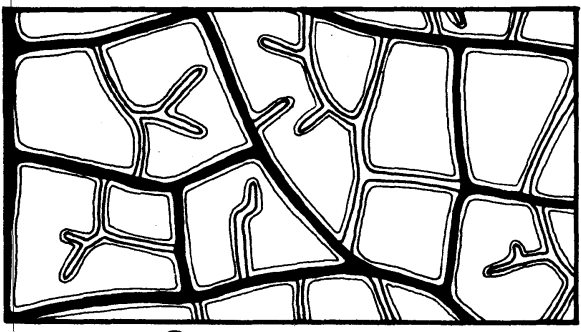

C. Grupo 3

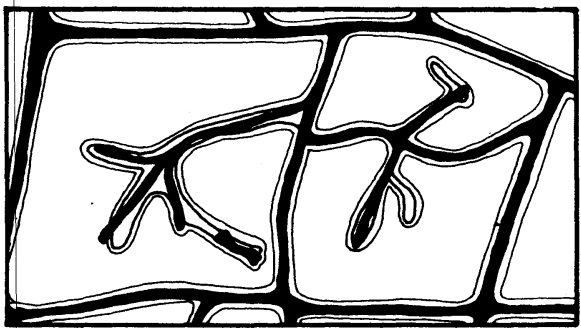

\section{E. Grupo 4}

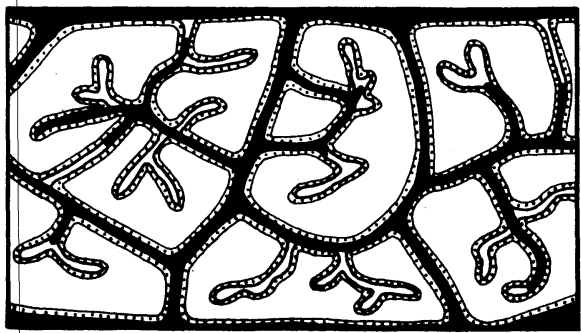

\section{G. Grupo $4 \mathrm{a}$}

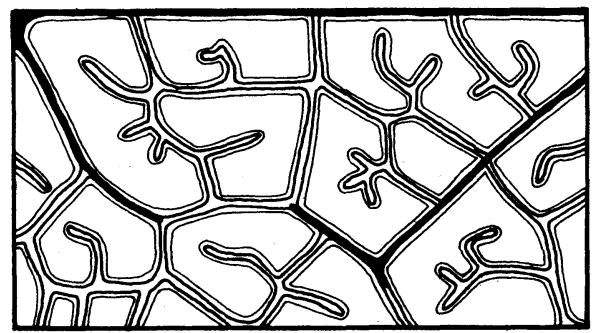

\section{B. Grupo 2}

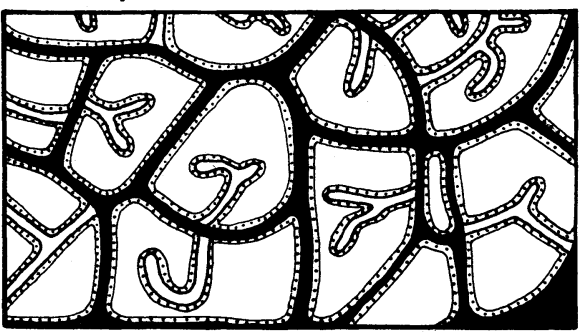

D. Grupo 3 a

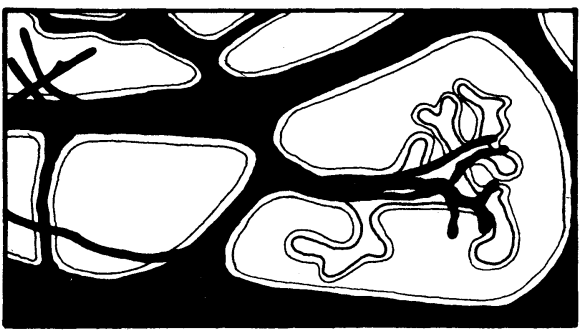

\section{F. Grupo 4}

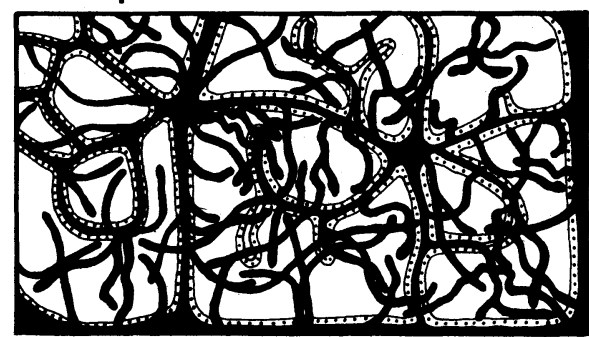

H. Grupo 4 a

Lámina 1. Venación menor anisodictia. Fig. A, B.atrata (Hinton 1378); Fig. B, B.herbacea (Yeshoda 207); Fig. C, B.catalpaefolia ssp. africana (Benoit 458); Fig. D, B.divaricata (Smith 2366); Fig. E, B.implacabilis (Krapovickas et al. 23074); Fig. F, B.melastomaefolia (Irwin et al. 12061); Fig. G, B.obtusata (Spruce 6024); Fig. H, B.rhamnifolia (Gutierrez 813). 
subgrupo corresponden a las secciones Vahihara, Crassipetala, Urticifolia e Incasica (Lám. 1, C).

El tamaño de las aréolas es relativamente reducido en todas las especies. El número de vénulas varía, son escasas en B.angulata y numerosas en B.hirsuta. Los extremos de las vénulas están constituídos por 1 ó 2 filas de traqueidas espiraladas por ejemplo en B.ivorensis, mientras en B.erosa y B.loxensis hay grupos de tres o más traqueidas espiraladas o escalariformes. En B.catalpaefolia ssp. africana y B.hirsuta se pueden presentar elementos traqueales cortos, punteados.

SUBGRUPO 3a: Vaina de los hacecillos intermedia, con elementos especializados hasta las venas que delimitan las aréolas y parenquimática al final. Incluye especies de las secciones Vahihara, Incasica y Crassipetala (Lám. 1, D).

La cantidad de venas con extensiones de la vaina es variable: en algunas especies sólo las poseen las venas mayores, mientras en otras se las encuentra en la mayor parte de las venas.

Las aréolas son de tamaño reducido; las vénulas pueden ser escasas como en B.catalpaefolia o numerosas como en B.Lopez-Mirandae y B.Weberbaueri. Los extremos de las vénulas están constituídos por 1 ó 2 traqueidas en B.Humbertiana, mientras en B.Lopez-Mirandae con frecuencia se observan numerosas traqueidas espiraladas o escalariformes. En casi todas las especies estas células aparecen acompañadas a menudo por elementos punieados, alargados, de paredes no muy gruesas.

GRUPO 4. Estas especies presentan esclerénquima holoneural. Las separaré en dos subgrupos de acuerdo a la constitución de la vaina.

SUBGRUPO 4: Vaina parenquimática. A veces las anastomosis de las venas se producen a través de la vaina. Comprende especies de 3 secciones. La mayoría de ellas presentan extensiones en todas las venas exceptuando las venillas que limitan las aréolas. B.mollis se distingue por poseer extensiones sólo en las venas mayores.

En las especies que corresponden a la sección Urticifolia no se observan elementos esclerenquimáticos en el mesófilo. Las venillas que cierran las aréolas corresponden al $5^{\circ}$ ó $6^{\circ}$ orden. Las aréolas son 
de tamaño variable, las de mayor superficie se hallan en B.implacabilis. Las vénulas son abundantes y muy ramificadas. Están compuestas por 1, 2 o más traqueidas espiraladas o escalariformes, algunas veces con elementos dilatados en los extremos en B.triadenia. Los elementos esclerenquimáticos son generalmente alargados, con paredes gruesas y con espículas. En las últimas venas ỳ vénulas se pueden encontrar elementos más cortos y provistos de puntuaciones simples.(Lám. 1, E).

Las especies que pertenecen a las secciones Crassipetala y Byttneria presentan fibroesclereidas muy largas, con extremos o brazos retorcidos que penetran el mesófilo. Son células de paredes gruesas, espiculadas, con puntuaciones simples. Las venillas que delimitan las aréolas pertenecen del $4^{\circ}$ al $7^{\circ}$ orden.(Lám. $1, \mathrm{~F}$ y $4, \mathrm{C}$ ).

La venación menor de las especies de la sección Byttneria presenta algunas características diferenciales. Las venạs están provistas de haces robustos de elementos esclerenquimáticos, tanto en el haz como en el envés. En B.jaculifolia en corte transversal se ven, además de las fibras perifloemáticas, casquetes subepidérmicos de fibroesclereidas. En algunas especies, como B.scalpellata, estos casquetes están constituídos por esclereidas cortas, de sección rectangular en corte longitudinal, con paredes gruesas, provistas de numerosas puntuaciones simples.

El mesófilo es equifacial en la mayoría de las especies; se observan estomas tanto en la epidermis abaxial como en la adaxial. Generalmente hay dos bandas subepidérmicas de parénquima clorofiliano, y entre ambas una capa de parénquima con pocos cloroplastos, cuyo espesor es variable, bastante grande cerca de las venas mayores. Por esta razón, en muchos casos se vuelve difícil el reconocimiento de la vaina de los hacecillos menores en corte transversal.

Las especies de esta sección muestran una cierta tendencia a la areolación incompleta. Las aréolas son generalmente muy amplias e irregulares, con vénulas muy ramificadas. Las ramas están formadas por 2 o más filas de traqueidas espiraladas y son bastante abultadas en algunas especies como B.melastomaefolia. Algunas veces como en B.elliptica y B.petiolata aparecen además elementos punteados. SUBGRUPO 4a: Vaina intermedia, con elementos especializados 
hasta las últimas venas y parénquima en las vénulas. En algunas especies las células de la vaina tienen forma irregular, con prominencias que penetran el mesófilo. En otras especies hay también idioblastos que contienen cristales. La frecuencia de extensiones de la vaina varía, en B.coriacea y B.rhamnifolia las presentan la mayor parte de las venas, mientras en B.dahomensis y B.ancistrodonta sólo las poseen las venas mayores.

Las especies que corresponden a Vahihara, Crassipetala e Incasica presentan elementos esclerenquimáticos solamente acompañando las venas, excepto B.australis y B.besalampensis que muestran algunos brazos penetrando el mesófilo. Las venillas que cierran las aréolas pueden ser del $5^{\circ}$ al $7^{\circ}$ orden. El tamaño de las aréolas varía, desde muy grande en B.australis a reducido en B.rhamnifolia. El número de vénulas puede ser relativamente bajo como en B.nitidula y $B$. lobata o elevado como en B.australis; las vénulas pueden ser simples o ramificadas. Las ramas están constituídas por 1 ó 2 filas de traqueidas en B.lucida y B.lobata y en las demás especies se encuentran también otras formadas por grupos de 3 o más traqueidas espiraladas o escalariformes. Además se ven con frecuencia elementos cortos punteados y en B.Asplundii y B.nitidula algunas vénulas están formadas exclusivamente por estas células. Los elementos esclerenquimáticos tienen paredes gruesas, con espículas, y su longitud varía: generalmente los que acompañan a las vénulas son más cortos que los que se hallan junto a las venas (Lám. 1, G y 4, D-E).

Las especies que corresponden a la sección Urticifolia se distinguen del resto del género por las características del esclerénquima foliar.

B.urosepala difiere de las demás porque absolutamente todas las venas $\mathbf{y}$ vénulas están acompañadas por elementos esclerenquimáticos que sin embargo no penetran el mesófilo. Junto a las venas menores y vénulas se encuentran verdaderas braquiesclereidas, con paredes muy gruesas provistas de puntuaciones simples. En esta especie se vuelve prácticamente imposible la distinción entre los elementos esclerenquimáticos propiamente dichos y los que corresponden "la vaina. Por su posición estas células constituirían la vaina, pero por su estructura son verdaderas esclereidas (Lám. 5, J-K). 
B.rhamnifolia y B.coriacea presentan esclereidas gigantes acompañando las venas $\mathrm{e}$ invadiendo totalmente el mesófilo foliar. La cantidad de fibroesclereidas presentes varía en los distintos ejemplares, posiblemente en relación con factores ambientales o genéticos (Bailey, 1944: 219). En ambas especies las aréolas son de tamaño variable, reducidas en algunos especímenes y amplias en otros; las vénulas pueden ser simples o diversamente ramificadas. Las ramas están formadas por 1 ó 2 traqueidas espiraladas, a veces más en algunos ejemplares de B.rhamnifolia. La vaina de los hacecillos parece más especializada en B.coriacea, ya que sus células tienen paredes ligeramente más gruesas (Lám. 1, H).

\section{Venación menor isodictia (*)}

Este tipo de venación se caracteriza por presentar aréolas de tamaño reducido y forma poligonal, con escasas vénulas simples rectas o curvas, o excepcionalmente bifurcadas (Wylie, 1946: 202, Tilia americana). Casi nunca hay más de una vénula por aréola. La mayor parte de las especies presenta extensiones de la vaina en casi todas las venas (Lám. 2).

GRUPO 5. Comprende unas pocas especies con esclerénquima mononeural, y vaina parenquimática. En B.rubriflora muchas veces los elementos traqueales no se anastomosan directamente entre sí sino a través de células de la vaina. Los elementos esclerenquimáticos, que se observan solamente en las venas primarias,son fibras típicas (Lám.2,A).

El tamaño de las aréolas presenta una pequeña variación: en $B$. flaccida se observan las más grandes y en B.rubriflora las más pequeñas. Las venillas que delimitan las aréolas corresponden al $5^{\circ}$ ó $6^{\circ}$ orden. Las vénulas, rectas generalmente, están formadas por 1 ó 2 filas de traqueidas espiraladas.

(*) Del griego isos: parecido y diktyon: red. 


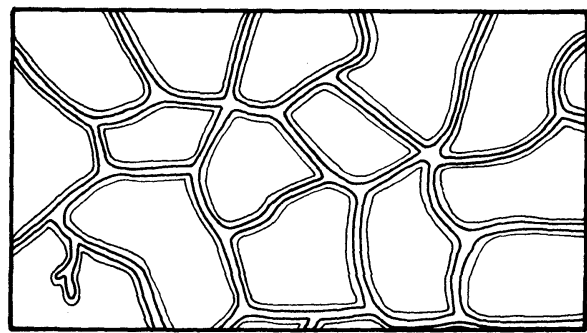

A. Grupo 5

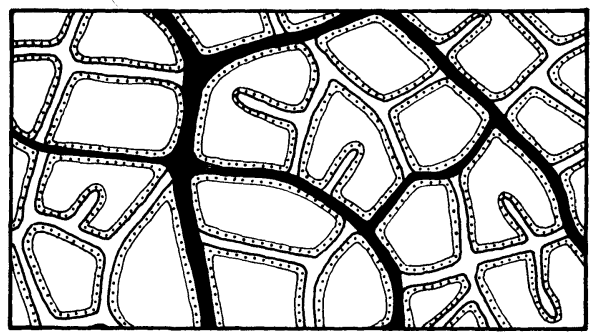

C. Grupo 6a

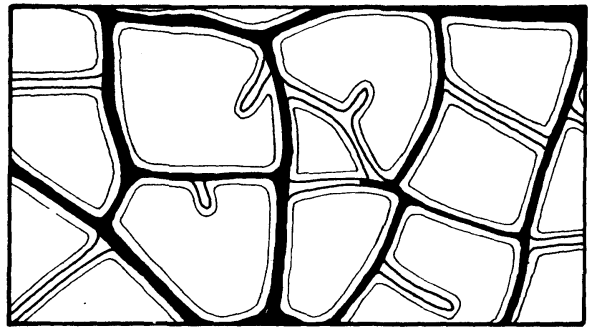

F. Grupo 7

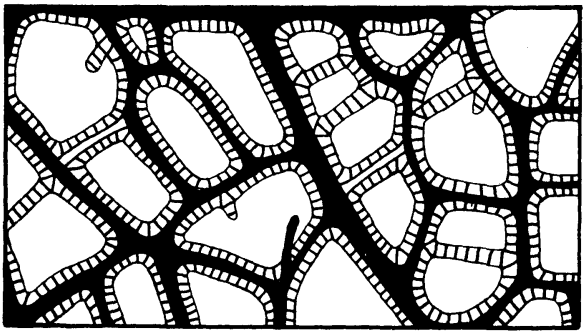

G. Grupo 7b

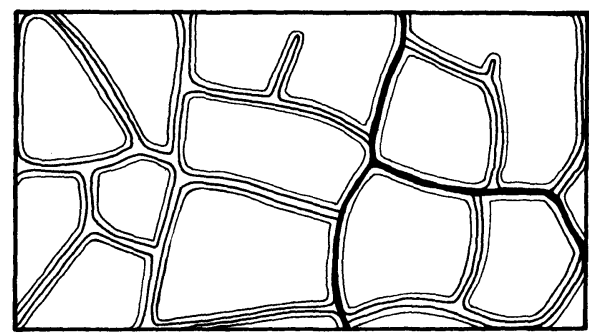

B. Grupo 6

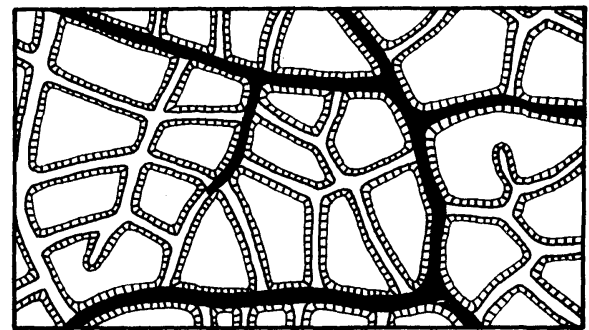

D. Grupo 6 b

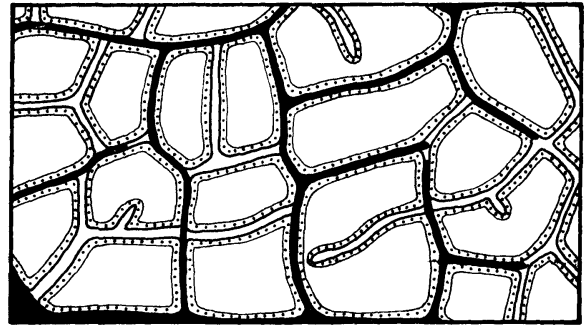

\section{F. Grupo 7a}

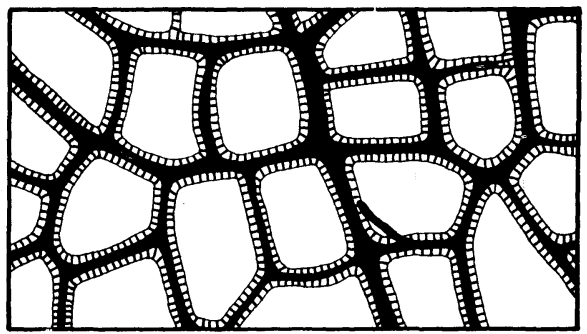

H. Grupo 8

Lámina 2. Venación menor isodictia. Fig. A, B.flaccida (Van Steenis 18022); Fig. B, B.oranensis (Cristóbal 650); Fig. C, B.heteromorpha (Peltier 945); Fig. D, B.grandifolia (Lau 261); Fig. E, B.celebica (Warburg s/n); Fig. F, B.heterophylla (Blackburn s/n); Fig. G, B.Curtisii (Bar̀tlett 7310); Fig. H, B.asłerotricha (Ducke 1096). 
GRUPO 6. Las especies de este grupo presentan esclerénquima oligoneural. Los elementos esclerenquimáticos son largos y delgados, con paredes gruesas; en las especies que poseen vaina especializada son difícilmente visibles en la hoja diafanizada, se los observa mejor en corte transversal. Las últimas venas que delimitan las aréolas pertenecen al $6^{\circ}$ ó $7^{\circ}$ orden. Las vénulas están formadas por 1 ó 2 filas de traqueidas espiraladas o escalariformes o solamente por elementos de la vaina. Se distinguen tres subgrupos de acuerdo al tipo de vaina (Lám. 2, B-D y 4, F-G).

SUBGRUPO 6: con vaina parenquimática. B. oranensis presenta extensiones sólo en las venas mayores y algunas de mediano grosor.

SUBGRUPO 6a: con vaina intermedia.

SUBGRUPO 6b: con vaina diferenciada. En estas especies, particularmente en B.fruticosa, muchas de las venillas y vénulas están formadas solamente por células de la vaina, faltando los elementos traqueales espiralados. El tamaño de las aréolas es muy reducido en $B$. pescapraeifolia y un poco mayor en B.fruticosa.

GRUPO 7. Las especies aquí reunidas presentan esclerénquima polineural. Los elementos esclerenquimáticos son largos, delgados, de paredes relativamente gruesas. Se observan muy bien en la hoja diafanizada en las especies que tienen vaina parenquimática, no así en aquellas cuya vaina es diferenciada.

El tamaño de las aréolas muestra una cierta fluctuación: B.fulva y B.Jackiana presentan las aréolas más pequeñas, mientras B.ambongensis y B.celebica tienen las más amplias. Las últimas venas que delimitan las aréolas pueden ser del $5^{\circ}$ al $8^{\circ}$ orden.

Las vénulas están formadas por 1 ó 2 filas de traqueidas espiraladas en B.Decaryana; en B.scabrida y B.vitifolia pueden haber 3 o más filas de traqueidas; en B.Curtisii las vénulas, muy escasas, están formadas por elementos de la vaina.

Se diferencian 3 subgrupos sobre la base del tipo de vaina:

SUBGRUPO 7: con vaina parenquimática (Lám. 2, E y 4, H).

SUBGRUPO 7a: con vaina intermedia. En algunas de estas especies, como B.voulily y B.ambongensis, las vénulas pueden presentar 
elementos cortos y punteados (Lám. 2, F y 4, I).

SUBGRUPO 7b: con vaina diferenciada. Estas especies presentan frecuentemente las últimas venillas y las vénulas formadas exclusivamente por células de la vaina. B.uaupensis se distingue de las demás porque presenta extensiones solamente en las venas mayores(Lám.2,G).

GRUPO 8. Comprende 4 especies con vaina diferenciada y esclerénquima holoneural. Los elementos esclerenquimáticos, de paredes gruesas, son alargados, con bracitos cortos de extremos redondeados proyectados hacia las aréolas (Lám. 2, H y 4, J).

Todas las especies presentan aréolas de superficie reducida y escasas vénulas; éstas en la mayoría de los casos están formadas solamente por células de la vaina. Además en B.Mastersii y B.attenuatifolia las últimas venas carecen de elementos espiralados, estando formadas solamente por células de la vaina, acompañadas o no por elementos esclerenquimáticos (Lám. 5, D).

\section{Discusión}

Relación de la venación menor con la taxonomía del género

Cristóbal (1976) estructuró el género Byttneria dividiéndolo en 6 secciones que son: Byttneria, Incasica, Crassipetala, Vahihara, Urticifolia y Gerontogaea.

Analizando la venación en relación con la división taxonómica del género se pueden apreciar algunos detalles significativos.

Las especies de la sección Byttneria presentan el mismo esquema de venación: anisodictia, con vaina parenquimática y esclerénquima holoneural. Estas especies presentan un patrón muy homogéneo, caracterizado por sus aréolas muy grandes, a menudo con varias vénulas cada una. Las vénulas son robustas y muy ramificadas. Esta sección se diferencia fácilmente de las demás por la ordenación equifacial de los componentes del mesøfilo en casi todas la especies, y el notable incremento de las estructuras de sostén. La mayoría de las 
venas están acompañadas por gruesos haces de fibras, incluídos en las extensiones de la vaina. Esto se refleja en la exomorfología porque las hojas de esta sección son las únicas del género que poseen venas prominentes tanto en la cara abaxial como en la adaxial. Hay otros caracteres vegetativos que individualizan a la sección Byttneria, como la posesión de nectarios foliares uniaperturados y tallos con sección poligonal por la presencia de cordones colenquimáticos o esclerenquimáticos superficiales.

La sección Vahihara es la que presenta mayor variabilidad. La venación menor isodictia es característica exclusiva de un grupo du especies de esta sección, y entre ellas hay algunas que poseen vaina diferenciada, cuya presencia es también un rasgo distintivo.

La sección Urticifolia presenta venación menor anisodictia, pero posee caracteres extremos: hay especies con vaina parenquimática $\mathbf{y}$ esclerénquima mononeural, y otras como B.coriacea y B.rhamnifolia que poseen vaina intermedia y una cantidad extraordinaria de fibroesclereidas que atraviesan el mesófilo. B.urosepala se caracteriza también por la abundancia de elementos esclerenquimáticos, aunque en este caso son braquiesclereidas que sólo se encuentran a lo largo de venas $\mathbf{y}$ vénulas.

Función y estructura de la vaina fascicular

Las puntuaciones tan notables de las células de las vainas diferenciadas y su topografía, recuerdan el tejido de transfusión de hojas de gimnospermas.

Hasta ahora no ha sido aclarado satisfactoriamente el origen del tejido de transfusión, pero se cree que funcionalmente está relacionado con la traslocación entre el haz vascular y el mesófilo.

Los autores que se han ocupado de este problema consideran improbable que el tejido de transfusión y la vaina fascicular de las venas foliares de dicotiledóneas sean homólogos. Sin embargo, me parece que existe una analogía desde el punto de vista funcional, pues los estudios realizados coinciden en sugerir para ambas estructuras el rol de conducción entre los hacecillos y el mesófilo.

Armacost (1944) anticipó que la vaina fascicular podría presentar 
especializaciones diversas. El hallazgo de distintos tipos de vaina en las hojas de Byttneria confirma nuevamente dicha suposición. Lo llamativo en este caso es que las únicas especies del género que poseen vaina diferenciada (con células lignificadas) son lianas de la selva tropical, es decir higrófitas, tanto americanas como africanas.

Sería muy interesante determinar cuáles son los factores que condicionan la aparición de este caracter xeromorfo en Byttneria. La presencia de vaina diferenciada no parece estar correlacionada con el hábitat, pues no todas las especies que habitan en la selva la poseen. Por otra parte, las vainas de tipo intermedio y parenquimático, aparecen tanto en especies que son lianas como entre las que son arbustos erectos $y$ apoyantes.

\section{Conclusiones}

El análisis de los factores que componen la venación menor de Byttneria me ha permitido obtener algunas conclusiones.

La venación menor anisodictia aparece en todas las secciones del género, en tanto que la venación menor isodictia aparece únicamente en 35 de las 60 especies de la sección Vahihara. Ambos tipos de venación se encuentran en toda el área geográfica del género.

La vaina fascicular parenquimática es un carácter común a todas las secciones, mientras la vaina intermedia aparece en especies de 4 secciones y la vaina diferenciada solamente en un cierto número de especies de la sección Vahihara.

La cantidad de esclerénquima foliar es muy variable, si bien un gran número de especies presenta esclerénquima holoneural y solamente unas pocas poseen esclerénquima mononeural.

Relacionando estas observaciones, me inclino a considerar la venación anisodictia con vaina parenquimática y esclerénquima oligoneural como el tipo más primitivo dentro del género. Este esquema corresponde al grupo 2 del cuadro 1 , en el que se hallan representadas todas las secciones del género exceptuando la sección Byt tneria (Lám.3).

A partir de este esquema se habrían derivado los otros, siguiendo 


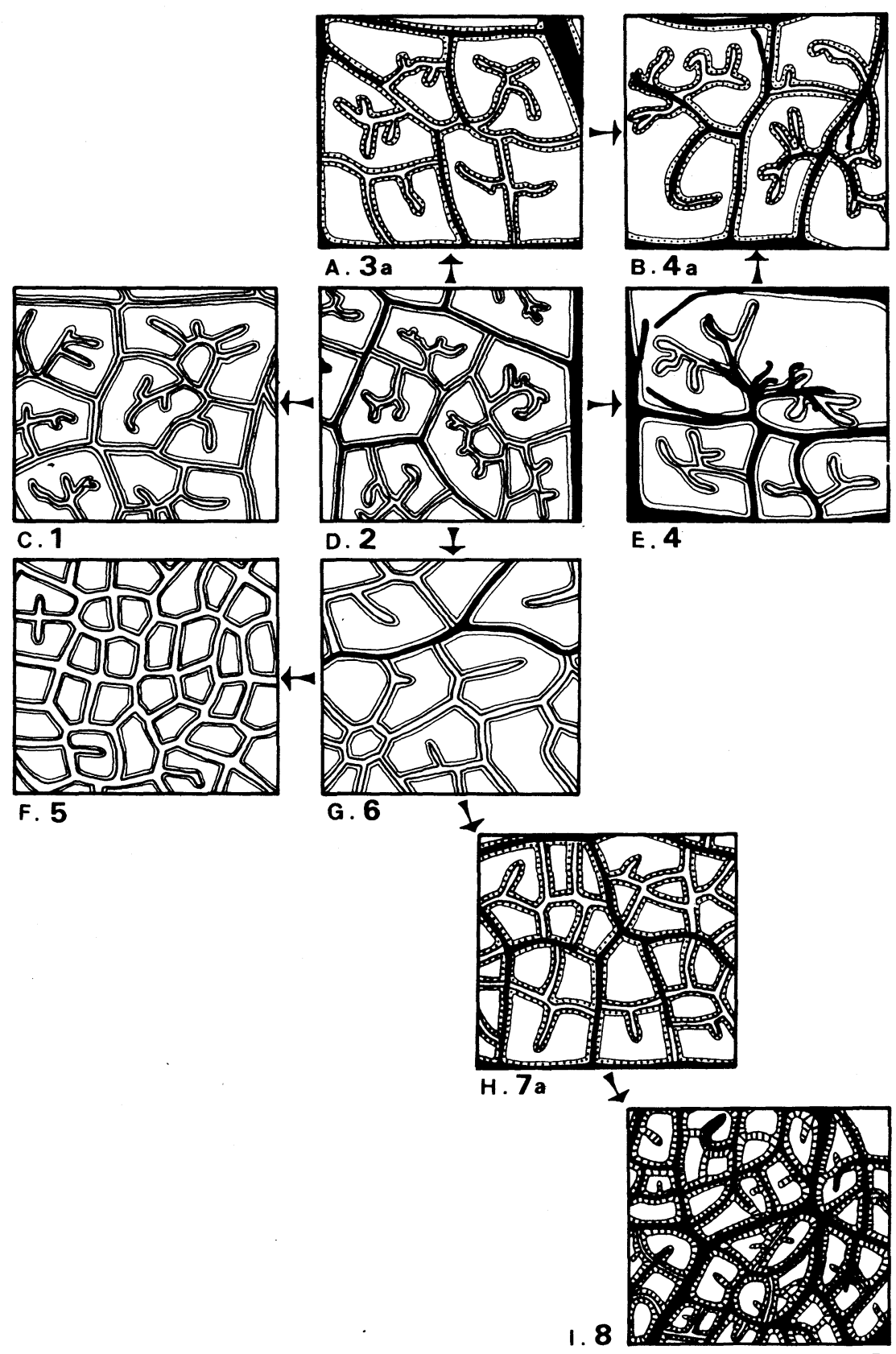

Lámina 3. Cuadro de relaciones. Fig. A, B.cordifolia (Ducke 925); Fig. B, B.australis (Ule 1001); Fig. C, B.Beyrichiana (Glaziou 8571); Fig. D, B.glabrescens (Ellenberg 1321); Fig. E, B.scabra (Krap. y Crist. 12050); Fig. F, B.Bernieri (Res.Nat.Madag. 10297); Fig. G, B.Baronii (Leandri et al. 2810); Fig. H, B.vitifolia (Boivin 2137); Fig. I, B.Piresii (Rodriguez 79). 
distintas líneas de especialización. La primera llevaría al esquema del grupo 1, por simplificación del esclerénquima foliar. La segunda originaría el esquema del subgrupo 4, por un marcado incremento de las estructuràs esclerenquimáticas. Una tendencia similar fue observada por Bailey y Nast (1944: 219) en algunos géneros de Winteraceae.

Con la tercera línea se llegaría al esquema del subgrupo 4a, que ofrece complejidad creciente no sólo en la morfología y disposición del esclerénquima, sino al mismo tiempo en la estructura de la vaina fascicular. En este sentido, B.rhamnifolia y B.coriacea presentan el grado más alto de especialización.

La última línea daría origen a la venación menor isodictia, mediante la reducción del tamaño de las aréolas y del número de vénulas. Esta línea muestra distintos niveles de organización de acuerdo al tipo de vaina y de esclerénquima foliar. Las especies más complejas son las que forman el grupo 8 (cuadro I): B.asterotricha, B.attenuatifolia, B.Mastersii y B.Piresii.

\section{Glosario}

AREOLAS: (Pray, 1954: areoles = islets) las mallas de menor tamaño en el retículo formado por las venas menores, con o sin vénulas en su interior.

VENULAS: (Hickey, 1973: veinlets, traducción de Zardini, 1974) venas últimas de la hoja que terminan libremente en el interior de las aréolas.

VAINA FASCICULAR: (Foster, 1949: bundle sheath = border parenquima en Armacost, 1944) revestimiento celular de las venas foliares mayores y menores (Carlquist, 1958).

Algunos autores como Armacost (1944) y Wylie (1943) aconsejan no identificar los revestimientos de las venas mayores provistos de tejidos de sostén con los de las venas menores. Prefiero seguir el criterio de Carlquist, que habla de "vaina" y "extensiones" más o menos prominentes incluso cuando se refiere a la vena principal. En Byttneria he podido observar que así como las venas de distinto or- 
den disminuyen gradualmente de grosor y complejidad, también lo hacen las vainas que las recubren, de modo que es prácticamente imposible establecer una división.

EXTENSIONES DE LA VAINA: (Sheath extensions: Esau en Wylie 1952) formadas por células generalmente similares a las de la vaina, que se extienden desde ésta hacia una o ambas epidermis.

\section{- Especies estudiadas (*)}

\section{B.abutiloides St. Hil. et Naud. (sect. Urticifolia)}

T. anisodictia. G. 3. AR. tamaño variable. VEN. frecuentes, simples o ramificadas, formadas por 1 ó 2 filas de traqueidas espiraladas; a veces se observan grupos de elementos cortos en los extremos. VAI. parenquimática. EXT. presentes sólo en las venas principales. ESCL. polineural. CRIST. numerosas drusas contenidas en células de la vaina.

MAT.EST. Brasil. Gardner 326.

\section{B.aculeata (Jacq.) Jacq. (sect. Crassipetala)}

T. anisodictia. G. 2. AR. amplias, forma variable. VEN. numerosas, generalmente muy ramificadas, robustas, formadas por 1 o 2 filas de traqueidas espiraladas. Con frecuencia los extremos formados pôr grupos de elementos cortos, dilatados. VAI. parenquimática. EXT. presentes en las venas principales solamente. ESCL. oligoneural. CRIST. en el ejemplar 27269 hay drusas acompañando las venas.

MAT.EST. Colombia. García Barriga 12130; Panamá. Gatún. Canal Zone. 17 VII 1923. Standley 27269 (US); Polinesia. St.John 14450.

\section{B.affinis Pohl (sect. Byttneria)}

T. anisodictia. G. 4. AR. amplias, de forma variable. VEN. numerosas, ramificadas, robustas, formadas por 2 o más filas de traqueidas espiraladas y generalmente más en los extremos que son abultados. VAI. parenquimática. EXT. faltan sólo en las venillas que cierran las aréolas. ESCL. holoneural; fibroesclereidas de paredes gruesas, espiculadas, con brazos penetrando el mesófilo. CRIST. drusas acompañando las venas.

MAT.EST. Brasil. Mello Filho 1909.

(*) Abreviaturas usadas: T. Tipo de venación; G. Grupo; AR. Aréolas; VEN. Vénulas; VAI. Vaina; EXT. Extensiones de la vaina; ESCL. Esclerénquima; CRIST. Cristales; OBS. Observaciones. MAT.EST. Material estudiado. (Los ejemplares citados en Cristóbal, 1976, figuran abreviados). 


\section{B.ambongensis J.Ar. (sect. Vahihara)}

T. isodictia. G. 7a. AR. reducidas. VEN. escasas, generalmente simples, formadas por 1 ó 2 filas de traqueidas espiraladas y a veces con elementos punteados; muchas veces los extremos formados por elementos dilatados. VAI. intermedia. EXT. presentes excepto en las venillas que cierran las aréolas. ESCL. polineural, elementos largos y delgados. CRIST. algunos prismáticos acompañando las venas. MAT.EST. Madagascar. Perrier 5385.

\section{B.ambongensis ssp. villosa J.Ar. (sect. Vahihara)}

T. isodictia. G. 7a. AR. reducidas. VEN. muy escasas, no ramificadas, formadas por una fila de traqueidas espiraladas, algunas veces con elementos punteados. VAI. intermedia. EXT. presentes, faltan en muchas de las venillas que cierran las aréolas. ESCL. polineural, elementos largos y delgados. CRIST. drusas acompañando las venas mayores, cristales prismáticos en el mesófilo.

MAT.EST. Madagascar. Perrier 5392 (P).

\section{B.ancistrodonta Mildbr. (sect. Crassipetala)}

T. anisodictia. G. 3a. AR. tamaño y forma variables. VEN. numerosas, simples o ramificadas, formadas por 2 o más filas de traqueidas espiraladas o escalariformes, y a veces elementos punteados. Con frecuencia se observan elementos dilatados en los extremos. VAI. intermedia. EXT. presentes solamente en las venas mayores. ESCL. polineural. CRIST. no se observan. OBS. hay grandes bolsas de mucílago en el mesófilo.

MAT.EST. Perú. Tessmann 5294.

\section{B.andamanensis Kurz.(sect. Vahihara)}

T. isodictia. G. 5. AR. muy reducidas. VEN. muy escasas, simples, formadas por 1 fila de traqueidas espiraladas, ocasionalmente con elementos dilatados en los extremos. VAI. parenquimática. EXT. presentes, faltan en las últimas venillas. ESCL. mononeural. CRIST. no se observan.

MAT.EST. Vietnam. Pierre 5478.

\section{B.angulata Hassk. (sect. Vahihara)}

T. anisodictia. G. 3. AR. tamaño y forma variables. VEN. poco frecuentes, simples a ramificadas, formadas por 1, 2 o más traqueidas espiraladas y a veces elementos punteados. En algunos casos los extremos formados por traqueidas dilatadas. VAI. parenquimática. ESCL. polineural, elementos largos de paredes gruesas. CRIST. prismáticos, acompañando las venas y también en el mesófilo. MAT.EST. Java. Cult.Jard.Buitenzorg. 1 XII 1904. Hochreutiner 40 (NY). 


\section{B.Aristeguietae Cristób. (sect. Crassipetala)}

T. anisodictia. G. 3a. AR. reducidas, forma variable. VEN. numerosas, simples o ramificadas, formadas por 1, 2 o más filas de traqueidas escalariformes y espiraladas y a veces con elementos punteados. Los extremos están formados frecuentemente por grupos de elementos cortos. VAI. intermedia. EXT. parecen existir en las venas gruesas; faltan en las venillas que cierran aréolas. ESCL. polineural. elementos largos de paredes gruesas, espiculados. CRIST. algunos prismáticos acompañando las venas.

MAT.EST. Colombia. Dugand y Jaramillo 2862.

\section{B.Asplundii Cristób. (sect. Crassipetala)}

T. anisodictia. G. 4a. AR. reducidas, forma variable. VEN. numerosas, simples o diversamente ramificadas, formadas por 1, 2 o más filas de traqueidas espiraladas o escalariformes y frecuentemente con elementos punteados, dilatados en los extremos. VAI. intermedia. ESCL. holoneural, elementos alargados, de paredes gruesas, espiculados. CRIST. drusas acompañando las venas.

MAT.EST. Perú. Ferreyra 10882.

\section{B.asterotricha Mildbr. (sect. Vahihara)}

T. isodictia. G. 8. AR. reducidas. VEN. escasas, simples, formadas por traqueidas espiraladas o solamente por células de la vaina. VAI. diferenciada a veces las últimas venas están formadas sólo por células de la vaina. EXT. presentes, faltan en algunas venillas que cierran aréolas. ESCL. holoneural, elementos largos, de paredes gruesas, algunos de los cuales penetran el mesófilo. CRIST. en el ejemplar 5535 el mesófilo y las venas presentan cristales prismáticos.

MAT.EST. Brasil. Ducke 1096 y Krukoff 5535.

\section{B.atrata Bullock (sect. Crassipetala)}

T. anisodictia. G. 1. AR. reducidas, forma variable. VEN. numerosas, simples o ramificadas, formadas por 1 ó 2 filas de traqueidas espiraladas. A veces los extremos abultados formados por grupos de elementos. VAI. parenquimática. EXT. presentes excepto en las venas que cierran las aréolas. ESCL. mononeural. CRIST. no se observan.

MAT.EST. México. Hinton 1378.

\section{B.attenuatifolia Cristób. (sect. Vahihara)}

T. isodictia. G. 8. AR. muy reducidas. VEN. muy escasas, simples, formadas por traqueidas espiraladas o escalariformes o solamente por células de la vaina. VAI. diferenciada. La mayor parte de las últimas venas están formadas sólo por células de la vaina. EXT. presentes excepto en las últimas venas que cierran las 
aréolas. ESCL. holoneural; elementos largos, de paredes gruesas, con algunos bracitos libres en el mesófilo. CRIST. prismáticos, en el mesófilo y acompañando las venas.

MAT.EST. Perú. Klug 567.

\section{B.aurantiaca Mildbr. (sect. Crassipetala)}

T. anisodictia. G. 2. AR. muy amplias, de forma variable. VEN. numerosas, muy ramificadas, formadas por 1 ó 2 filas de traqueidas espiraladas. VAI. parenquimática. ESCL. oligoneural; elementos largos y delgados. CRIST. no se observan. MAT.EST. Brasil. Irwin 48750.

\section{B.australis St.Hil. (sect. Crassipetala)}

T. anisodictia. G. 4a. AR. muy amplias, forma variable. VEN. simples a muy ramificadas, formadas por 1 a varias traqueidas espiraladas o a veces escalariformes, ocasionalmente con elementos punteados; algunas veces los extremos formados por elementos dilatados. VAI. intermedia. EXT. presentes en las venas mayores, a veces también en venas de grosor mediano. ESCL. holoneural, elementos esclerenquimáticos largos de paredes gruesas con algunos brazos penetrando el mesófilo. CRIST. en el ejemplar 15370 hay numerosas drusas acompañando las venas.

MAT.EST. Brasil. Ule 1001; Hatschbach 10425; Rambo 37525; Argentina. Krapovickas y Cristóbal 15370.

\section{B.Baronii J.Ar. (sect. Vahihara)}

T. isodictia. G. 6. AR. reducidas. VEN. escasas, simples, delgadas, formadas por una a varias traqueidas espiraladas. VAI. parenquimática. EXT. presentes excepto en las venas más delgadas. ESCL. oligoneural. CRIST. numerosos cristales prismáticos en la vaina y mesófilo.

MAT.EST. Madagascar. Antsalova. Antsingy vers Bevary. 27 I - 5 II 1960. Leandri et al. $2810(\mathrm{P})$.

\section{B.Beccarii Warb. (sect. Vahihara)}

T. isodictia. G. 7b. AR. reducidas. VEN. escasas, simples, formadas por células de la vaina. VAI. diferenciada. EXT. presentes excepto en algunas venillas que delimitan las aréolas. ESCL. polineural. CRIST. algunos prismáticos acompañando las venas.

MAT.EST. Borneo. Kuching. Sarawak. Haviland 941 (UC)

\section{B.benensis Britt. (sect. Vahihara)}

T. anisodictia. G. 3. AR. reducidas, forma variable. VEN. poco frecuentes, delgadas, simples o poco ramificadas, formadas por 1 a varias traqueidas espirala- 
das o escalariformes, muchas veces con elementos punteados en los extremos. VAI. parenquimática. EXT. presentes excepto en algunas venillas. ESCL. polincural. CRIST. no se observan.

MAT.EST. Bolivia. Rusby 1964 y 1249.

19. B.Bernieri Hochr. (sect. Vahihara)

T. isodictia. G. 5. AR. reducidas. VEN. escasas, simples, formadas por una fila de traqueidas espiraladas. VAI. parenquimática. EXT. presentes excepto en las venas más delgadas. ESCL. mononeural. CRIST. no se observan.

MAT.EST. Madagascar. Antsalova. 20 XII 1958. Res.Nat.Madag. 10297 (P).

20. B.besalampensis J.Ar. (sect. Vahihara)

T. anisodictia. G. 4a. AR. reducidas, forma variable. VEN. frecuentes, simples, o ramificadas, formadas por una a varias traqueidas espiraladas, algunas veces con elementos punteados. VAI. intermedia. ESCL. holoneural con bracitos libres en las aréolas. CRIST. no se observan.

MAT.EST. Madagascar. Decary 15621.

\section{B.Beyrichiana K.Sch. (sect. Crassipetala)}

T. anisodictia. G. 1. AR. reducidas, forma variable. VEN. numerosas, simples, ramificadas, formadas por una o dos filas de traqueidas espiraladas. Los extremos generalmente abultados formados por uno o varios elementos dilatados. VAI. parenquimática. ESCL. mononeural. CRIST. no se observan. MAT.EST. Brasil. Glaziou 8571.

22. B.biloba Baill. ssp. Grandidieri (H.Bn) J.Ar. var. Bauhinioides (Bak.) J.Ar. (sect. Vahihara).

T. isodictia. G. 7. AR. reducidas. VEN. escasas, generalmente simples, formadas por 1, 2 o más traqueidas espiraladas. VAI. parenquimática. EXT. parecen existir en las venas mayores. ESCL. polineural; elementos largos, delgados. CRIST. prismáticos, acompañando las venas y en el mesófilo.

MAT.EST. Madagascar. SW. Manasoa. Tanosy. 11 I 1913. Afzeluis s/n (UPS).

\section{B.catalpaefolia Jacq. (sect. Vahihara)}

T. anisodictia. G. 3a. AR. reducidas, forma variable. VEN. escasas, delgadas, poco ramificadas o simples, formadas por 1 a varias traqueidas espiraladas o escalariformes, pocas veces con elementos punteados. VAI. intermedia, con idioblastos conteniendo cristales. ESCL. polineural, elementos largos y delgados. CRIST. cúbicos ubicados en los idioblastos a lo largo de las venas. MAT.EST. Venezuela. Eggers 13352. 


\section{B.catalpaefolia ssp. africana (Mast.) Exell et Mendon. (sect. Vahihara)}

T. anisodictia. G. 3. AR. tamaño y forma variables. VEN. frecuentes, simples o ramificadas, formadas por 1 ó 2 filas de traqueidas espiraladas, a veces más en los extremos, ocasionalmente con elementos punteados. VAI. parenquimática, con idioblastos conteniendo cristales. EXT. presentes excepto en algunas venas menores. ESCL. polineural; elementos largos de paredes relativamente gruesas. CRIST. prismáticos en idioblastos, acompañando las venas.

MAT.EST. Congo Belge. Ghesquiere 6931; Cameroun. Benoit 458.

\section{B.catalpaefolia ssp. sidaefolia (St.Hil.) Cristób. (sect. Vahihara)}

T. anisodictia. G. 3. AR. reducidas, forma variable. VEN. frecuentes, simples o ramificadas, formadas por 1 ó 2 filas de traqueidas espiraladas, a veces más en los extremos o con elementos dilatados. VAI. parenquimática. EXT. presentes, faltan en las venas que delimitan aréolas. ESCL. polineural; elementos largos y delgados. CRIST. no se observan.

MAT.EST. Brasil. Glaziou 15451; Paraguay. Krapovickas et al. 14119.

\section{B.celebica Hochr. (sect. Vahihara)}

T. isodictia. G. 7. AR. tamaño variable, forma generalmente poligonal. VEN. escasas, generalmente simples, formadas por 1 fila de traqueidas espiraladas, delgadas, ocasionalmente con elementos punteados. VAI. parenquimática. EXT. no existen en las últimas venillas. ESCL. polineural; elementos largos, delgados. CRIST. prismáticos, a lo largo de las venas y el mesófilo.

MAT.EST. Ins.Celebes. Minahassa. 1888. Warburg s/n (NY).

\section{B.celtoides St.Hil. (sect. Urticifolia)}

T. anisodictia. G. 2. AR. tamaño variable, forma irregular. VEN. frecuentes, simples o ramificadas, formadas por 1 ó 2 filas de traqueidas espiraladas, a veces traqueidas dilatadas en los extremos. VAI. parenquimática. EXT. no hay sobre las últimas venillas. ESCL. oligoneural; elementos largos, delgados. CRIST. numerosas drusas acompañando las venas.

MAT.EST. Brasil. St.Hilaire 1059.

\section{B.cordata Lam. (sect. Incasica)}

T. anisodictia. G. 2. AR. reducidas, forma variable. VEN. numerosas, simples o ramificadas, formadas por 1 ó 2 filas de traqueidas espiraladas. Los extremos abultados a veces, formados por grupos de elementos cortos. VAI. parenquimática. ESCL. oligoneural; elementos alargados, de paredes no muy gruesas. CRIST. drusas acompañando las venas.

MAT.EST. Perú. Hutchinson y Ricardi 5003. 


\section{B.cordifolia Sagot (sect. Vahihara)}

T. anisodictia. G. 3a. AR. tamaño y forma variables. VEN. frecuentes, simples o ramificadas, formadas por 2 o más traqueidas espiraladas o escalariformes, a veces con elementos punteados. Frecuentemente presentan traqueidas dilatadas en los extremos. VAI. intermedia. ESCL. polineural. CRIST. no se observan.

MAT.EST. Brasil. Ducke 925.

\section{B.coriacea Britt. (sect. Urticifolia)}

T. anisodictia. G. 4a. AR. reducidas, relativamente amplias en los ejemplares 4104 y 4107. Forma variable. VEN. numerosas, simples o ramificadas, formadas por una a varias traqueidas espiraladas. VAI. intermedia, en algunos ejem plares con células diferenciadas incluso alrededor de las vénulas. EXT. presentes excepto en las últimas venillas. En algunas venas hay extensiones solamente hacia la epidermis adaxial. ESCL. holoneural; fibroesclereidas gigantes, de formas variadas, invadiendo el mesófilo además de acompañar las venas. CRIST. solamente dos ejemplares (562 y 670) carecen de ellos; en los demás hay numerosos cristales prismáticos acompañando las venas y en algunos ejemplares también los hay en el mesófilo.

MAT.EST. Brasil. Kuhlman 670 y 432; Perú. Tessmann 4104 y 4107.

\section{B.corylifolia Humb. et Bonpl. (sect. Incasica)}

T. anisodictia. G. 3. AR. reducidas, forma variable. VEN. numerosas, simples o ramificadas, robustas, formadas por 1 a varias traqueidas espiraladas. Con frecuencia se observan los extremos abultados formados por grupos de elementos cortos. VAI. parenquimática. EXT. presentes excepto en las venillas que delimitan las aréolas. ESCL. polineural; elementos largos, de paredes gruesas, espiculados, con algunos extremos en el mesófilo. CRIST. prismáticos y drusas contenidas en células de la vaina. No se observan en el ejemplar 20473.

MAT.EST. Colombia. Uribe Uribe 1566; Cuatrecasas 20473.

\section{B.crenulata Wall. ex Mast. (sect. Vahihara)}

T. isodictia. G. 6b. AR. reducidas, forma generalmente poligonal. VEN. muy escasas, formadas por traqueidas espiraladas o escalariformes o solamente por elementos de la vaina. VAI. diferenciada. EXT. presentes excepto en las venillas que delimitan las aréolas. ESCL. oligoneural. CRIST. no se observan.

MAT.EST. Viet-Nam. Pierre 3746.

\section{B.Curtisii Oliv. (sect. Vahihara)}

T. isodictia. G. 7b. AR. reducidas, forma generalmente poligonal. VEN. muy escasas, simples, formadas por elementos de la vaina. VAI. diferenciada; muchas de las últimas venas formadas sólo por sus células, sin elementos traqueales es- 
piralados. EXT. presentes, excepto en las venillas últimas. ESCL. polineural. CRIST. prismáticos, en el mesófilo y algunos acompañando las venas.

MAT.EST. Indonesia. Sumatra. Aek Kanopan Loendoeb concession. Koealoe. 17 IV 1927. Bartlett 7310 (MICH).

\section{B.dahomensis Hallé (sect. Crassipetala)}

T. anisodictia. G. 3a. AR. tamaño y forma variables. VEN. numerosas, simples o ramificadas, formadas por una a varias traqueidas espiraladas o escalariformes, muchas veces con elementos punteados. Con frecuencia los extremos son abultados, formados por grupos de traqueidas. VAI. intermedia. EXT. presentes solamente en las venas mayores. ESCL. polineural. CRIST. no se observan.

MAT.EST. Dahomey. Le Testu 218.

\section{B.Decaryana J.Ar. (sect. Vahihara)}

T. isodictia. G. 7a. AR. reducidas, forma poligonal. VEN. muy escasas, simples, formadas por una o dos filas de traqueidas espiraladas. VAI. intermedia. EXT. presentes especialmente hacia la epidermis adaxial. ESCL. polineural; elementos largos, delgados. CRIST. prismáticos, siguiendo las venas y también algunos en el mesófilo.

MAT.EST. Madagascar. Decary 14458.

\section{B.dentata Pohl (sect. Byttneria)}

T. anisodictia. G. 4. AR. generalmente muy amplias y de forma variable. VEN. numerosas, simples a muy ramificadas, robustas, formadas por una a 2 filas de traqueidas espiraladas o escalariformes, a veces más en los extremos que generalmente son abultados. VAI. parenquimática. EXT. presentes excepto en las venillas que cierran las aréolas. ESCL. holoneural; fibroesclereidas largas, de forma variable, cuyos extremos penetran el mesófilo. CRIST. hay drusas acompañando las venas excepto en el ejemplar 12473. OBS. mesófilo de estructura dorsiventral.

MAT.EST. Brasil. Pohl 2487; Irwin et al. 16883, 17442 y 17445; Paraguay. Krapovickas et al. 12621 y 12473.

\section{B.divaricata Benth. (sect. Crassipetala)}

T. anisodictia. G. 3a. AR. reducidas, forma variable. VEN. numerosas, simples o ramificadas, formadas por una a varias traqueidas espiraladas, a veces escalariformes, frecuentemente con elementos punteados. Muchas veces los extremos son abultados, formados por grupos de traqueidas. VAI. intermedia. EXT. presentes excepto en las venillas que cierran las aréolas. ESCL. polineural; elementos de longitud variable, con paredes grwesas, espiculados. CRIST. en el ejemplar 2366 hay cristales prismáticos acompañando las venas. 
MAT.EST. Paraguay. Rojas 1905; Guayana Británica. Schomburgk 205; Smith 2366.

\section{B.echinata Wall. (sect. Vahihara)}

T. isodictia. G. 6a. AR. reducidas. VEN. escasas, simples o bifurcadas, formadas por traqueidas espiraladas o escalariformes, algunas veces con elementos punteados. VAI. intermedia. EXT. presentes, excepto en las venillas que cierran las aréolas. ESCL. oligoneural, elementos lạrgos, de paredes gruesas. CRIST. cúbicos grandes acompañando las venas y pequeñas drusas en el mesófilo.

MAT.EST.Expedición du Me-Kong. 1866-1868. Thorel s/n (P).

39. B.Ekmanii Urb. (sect. Crassipetala)

T. anisodictia. G. 2. AR. reducidas, forma variable. VEN. numerosas, simples o ramificadas, robustas, formadas por 1 o dos filas de traqueidas espiraladas. Con frecuencia se observan elementos dilatados en los extremos. VAI. parenquimática, con idioblastos conteniendo cristales. EXT. presentes, excepto en las últimas venas. ESCL. oligoneural. CRIST. muy abundantes, prismáticos sobre las venas mayores y drusas sobre las venas menores.

MAT.EST. Haití. Ekman 6489.

40. B.elegans Ridl. (sect. Vahihara)

T. anisodictia. G. 2. AR. reducidas, forma variable. VEN. numerosas, simples o ramificadas, formadas por una o dos filas de traqueidas espiraladas, ocasionalmente con elementos punteados. Los extremos muchas veces formados por elementos dilatados. VAI. parenquimática. EXT. no hay sobre las últimas venillas. ESCL. oligoneural. CRIST. no se observan.

MAT.EST. Tailandia. Bangkok. Banang Sta. Pattani. 22 VII 1923. (UC 289063).

\section{B.elliptica Pohl (sect. Byttneria)}

T. anisodictia. G. 4. AR. muy amplias y de forma muy variable. VEN. numerosas, robustas, con extremos abultados, generalmente ramificadas, formadas por dos o más filas de traqueidas espiraladas, a veces con elementos punteados. VAI. parenquimática. EXT. presentes excepto en las venillas que cierran las aréolas. ESCL. holoneural; fibroesclereidas de paredes gruesas, cuyos extremos penetran el mesófilo. CRIST. drusas acompañando las venas.

MAT.EST. Brasil Irwin et al. 34272.

\section{B.ellipticifolia J.Ar. (sect. Vahihara)}

T. isodictia. G. 7b. AR. reducidas, poligonales. VEN. escasas, simples, cortas, formadas por traqueidas espiraladas o escalariformes o sólo por elementos de la vaina. VAI. diferenciada. EXT. presentes excepto en las venillas últimas. ESCL. polineural. CRIST. algunos prismáticos acompañando las venas.

MAT.EST. Madagascar. Decary 5672.

\section{B.erosa Gagnep. (sect. Vahihara)}

T. anisodictia. G. 3. AR. forma variable, tamaño reducido. VEN. frecuentes, ro- 
bustas, simples o ramificadas, formadas por varias filas de traqueidas espiraladas o escalariformes. Con frecuencia se observan grupos de elementos cortos, dilatados en los extremos. VAI. parenquimática. EXT. no hay en las venillas que cierran las aréolas. ESCL. polineural; elementos largos, delgados. CRIST. numerosos cristales prismáticos siguiendo las venas.

MAT.EST. Vietnam del Norte. Balansa 3902.

\section{B.Fernandesii Cristób. (sect. Crassipetala)}

T. anisodictia. G. 2. AR. tamaño variable y forma muy irregular. VEN. frecuentes, simples o ramificadas, delgadas, formadas por una o dos filas de traqueidas. VAI. parenquimática, con idioblastos conteniendo cristales. EXT. parecen existir en todas las venas, excepto algunas venillas últimas. ESCL. oligoneural; elementos largos de paredes gruesas. CRIST. drusas acompañando las venas.

MAT.EST. Brasil. Fernandes s/n (Herb.Cat. 1716).

\section{B.filipes Mart. ex K.Schum. (sect. Crassipetala)}

T. anisodictia. G. 2. AR. tamaño y forma variables. VEN. numerosas, simples o ramificadas, robustas, formadas por 1 a varias traqueidas espiraladas. Con frecuencia los extremos formados por grupos de elementos cortos. VAI. parenquimática. EXT. solamente en las venas mayores; en algunas venas de grosor mediano hay extensiones sólo del lado abaxial. ESCL. oligoneural. CRIST. el ejemplar 11495 presenta cristales prismáticos acompañando las venas.

MAT.EST. Argentina. Krapovickas y Cristóbal 11327; Pedersen 8307; Paraguay. San Bernardino. Lago Ipacaraí. 26 V 1964. Krapovickas y Cristóbal 11495 (CTES).

\section{B.flaccida Span. (sect. Vahihara)}

T. isodictia. G. 5. AR. tamaño variable, forma generalmente poligonal. VEN. muy escasas, simples, delgadas, formadas por 1 o dos traqueidas espiraladas, a veces escalariformes. VAI. parenquimática. ESCL. mononeural. CRIST. prismáticos en abundancia, siguiendo las venas y también en el mesófilo.

MAT.EST. Timor. Baneau. 15 XII 1953. Van Steenis 18022 (BM).

\section{B.flexuosa Killip (sect. Incasica)}

T. anisodictia. G. 2. AR. tamaño y forma variables. VEN. numerosas, simples o ramificadas, robustas, formadas por 1 a varias traqueidas espiraladas. VAI. parenquimática. EXT. presentes en las venas mayores solamente. ESCL. oligoneural. CRIST. numerosas drusas acompañando las venas, también cristales prismáticos. MAT.EST. Ecuador. André 4435.

\section{B.fruticosa K.Schum. (sect. Vahihara)}

T. isodictia. G. 6b. AR. reducidas, generalmente poligonales. VFN. escasas, simples (excepcionalmente bifurcadas), formadas por traqueidas espiraladas o escalariformes o solamente por elementos de la vaina. VAI. diferenciada. EXT. presentes en la mayor parte de las venas, excepto en las venillas que delimitan las 
aréolas. ESCL. oligoneural. CRIST. algunos cristales prismáticos en el mesófilo. MAT.EST. Tanganyika. Mhulumuzi. 10 V 1906. Zimmermann 1045 (US).

\section{B.fulva Poepp. et End. (sect. Vahihara)}

T. isodictia. G. 7b. AR. muy reducidas, forma poligonal. VEN. muy escasas, simples, formadas por traqueidas espiraladas o escalariformes o exclusivamente por elementrss de la vaina. VAI. diferenciada; algunas venas menores formadas solamente por éstas células, sin elementos espiralados. EXT. presentes excepto en algunas venillas que delimitan las aréolas. ESCL. polineural. CRIST. no se observan. MAT.EST. Brasil. Tocantins. 11 XI 1927. Ducke s/n. Herb. no 21053 (CTES).

\section{B.Gayana St.Hil. (sect. Vahihara)}

T. anisodictia. G. 3a. AR. reducidas, forma variable. VEN. frecuentes, simples o ramificadas, formadas por una o dos filas de traqueidas espiraladas o escalariformes, ocasionalmente con elementos punteados. Algunas veces presentan los extremos abultados formados por grupos de traqueidas. VAI. intermedia. EXT. presentes en venas mayores y en algunas de grosor mediano. No llegan a las venillas que delimitan las aréolas. ESCL. polineural. CRIST. no se observan. MAT.EST. Brasil. Luschnath s/n.

\section{B.genistella Tr. et Pl. (sect. Byttneria)}

T. anisodictia. G. 4. AR. muy amplias, de forma variable. VEN. numerosas, robustas, generalmente muy ramificadas, formadas por una a varias traqueidas espiraladas o escalariformes. VAI. parenquimática. EXT. sólo faltan en las venillas que delimitan aréolas. ESCL. holoneural; fibroesclereidas de paredes gruesas, cuyos extremos penetran el mesófilo. CRIST. drusas acompañando las vénas.

MAT.EST. Brasil. Murça Pires et al. 52357.

\section{B.glabrescens Benth. (sect. Incasica)}

T. anisodictia. G. 2. AR. tamaño y forma variables. VEN. frecuentes, delgadas, simples o diversamente ramificadas, formadas por 1 ó 2 filas de traqueidas espiraladas. El ejemplar 1382 presenta los extremos generalmente abultados, formados por grupos de elementos cortos. VAI. parenquimática; el ejemplar 1321 presenta idioblastos conteniendo cristales y grandes bolsas de mucílago. EXT. no llegan a las últimas venillas. ESCL. oligoneural; elementos largos, delgados, de paredes relativamente gruesas. CRIST. el ejemplar 1321 presenta numerosas drusas acompañando las venas.

MAT.EST. Perú. Tumbes. 7 V 1957. Ellemberg 1321 (U); Scolnik 1382.

53. B.Glazioui Hochr. (sect. Byttneria)

T. anisodictia. G. 4. AR. muy amplias, de forma variable. VEN. numerosas, ge- 
neralmente muy ramificadas, robustas, formadas por varias filas de traqueidas espiraladas, a veces escalariformes. VAI. parenquimática. EXT. faltan en las últimas venillas. ESCL. holoneural; fibroesclereidas de forma variable, con numerosos brazos libres en el mesófilo. CRIST. no se observan.

MAT.EST. Brasil. Irwin et al. 11205.

54. B.gracilipes Decne. ex Baill. (sect. Urticifolia)

T. anisodictia. G. 1. AR. muy amplias, forma irregular. VEN. numerosas, generalmente ramificadas, formadas por una o dos filas de traqueidas espiraladas. Muchas veces los extremos abultados formados por grupos de elementos. VAI. parenquimática. EXT. presentes, faltan en las venillas que delimitan las aréolas. ESCL. mononeural. CRIST. drusas acompañando las venas.

MAT.EST. Argentina. Cristóbal et al. 21; Maruñak 103.

\section{B.grandifolia DC. (sect. Vahihara)}

T. isodictia. G. 6b. AR. reducidas, forma poligonal. VEN. muy escasas, simples, formadas por traqueidas espiraladas o escalariformes, algunas veces sólo por la vaina. VAI. diferenciada. EXT. presentes excepto en las venillas que cierran las aréolas. ESCL. oligoneural. CRIST. algunos prismáticos en el mesófilo.

MAT.EST. China. Hainan. Ngai district. Naam Shan Leng. 14 VII 1932. Lau 261 (US).

\section{B.guineënsis Keay et Milne-Redhead (sect. Crassipetala)}

T. anisodictia. G. 2. AR. tamaño y forma variables. VEN. numerosas, simples o ramificadas, robustas, formadas por una o dos filas de traqueidas espiraladas, a veces más en los extremos. VAI. Parenquimática. EXT. presentes sólo en las venas mayores. ESCL. oligoneural; elementos largos, de paredes gruesas. CRIST. no se observan.

MAT.EST. Sierra Leona. Deighton 5030.

\section{B.Hatschbachii Cristób.(sect. Byttneria)}

T. anisodictia. G. 4. AR. amplias generalmente, forma muy variable. VEN. numerosas, simples o ramificadas, robustas, formadas por dos a varias filas de traqueidas espiraladas. En los extremos presentan grupos de elementos cortos, espiralados o escalariformes. VAI. parenquimática. EXT. faltan en las venillas que cierran las aréolas. ESCL. holoneural; fibroesclereidas largas, de paredes gruesas, con ex tremos retorcidos penetrando el mesófilo. CRIST. no se observan. MAT.EST. Brasil. Hatschbach 20042.

58. B.herbacea Roxb. (sect. Gerontogaea)

T. anisodictia. G. 2. AR. reducidas, forma variable. VEN. frecuentes, simples o 
diversamente ramificadas, formadas por 1 a varias traqueidas espiraladas, algunas veces con elementos punteados. VAI. parenquimática. EXT. no llegan hasta las venillas que cierran las aréolas. ESCL. oligoneural. CRIST. en el ejemplar 888 hay cristales prismáticos acompañando las venas mayores y en el mesófilo.

MAT.EST. India. Mooney 888; Yeshoda 207.

59. B.heteromorpha J.Ar. (sect. Vahihara)

T. isodictia. G. 6a. AR. reducidas, forma poligonal. VEN. escasas, generalmente simples, formadas por una o dos fillas de traqueidas espiraladas. VAI. intermedia. EXT. presentes, excepto en algunas de las venillas que cierran aréolas. ESCL. oligoneural. CRIST. no se observan.

MAT.EST. Madagascar. Antandrokomby. Lac. Alaotra. VI 1957. Peltier 945 (P).

60. B.heterophylla Hook. (sect. Vahihara)

T. isodictia. G. 7a. AR. reducidas, forma poligonal. VEN. escasas, generalmente simples, formadas por una o más filas de traqueidas espiraladas, ocasionalmente con elementos dilatados en el extremo. VAI. intermedia. EXT. en las venas que delimitan las aréolas generalmente hay extensiones sólo hacia la epidermis abaxial. ESCL. polineural; elementos largos, delgados. CRIST. algunos cristales prismáticos en la vaina.

MAT.EST. Mauritius et Madagascar. 17 VII 1863. Blackburn s/n (P).

\section{B.hirsuta Ruiz et Pav. (sect. Urticifolia)}

T. anisodictia. G. 3. AR. reducidas, forma variable. VEN. numerosas, simples o ramificadas, robustas, formadas por una a varias traqueidas espiraladas, a veces con elementos punteados o escalariformes. VAI. parenquimática. EXT. presentes en las venas mayores; parecen existir también en algunas venas medianas, pero no en las más delgadas. ESCL. polineural; elementos largos, de paredes gruesas, espiculados. CRIST. drusas a lo largo de las venas.

MAT.EST. Bolivia. Bang 2205.

\section{B.hirta J.Ar. (sect. Vahihara)}

T. anisodictia. G. 4a. AR. reducidas, de forma variable. VEN. frecuentes, simples o poco ramificadas, formadas por una a varias traqueidas espiraladas o escalariformes, a veces con elementos punteados. Ocasionalmente presentan los extremos engrosados formados por grupos de traqueidas. VAI. intermedia. EXT. no llegan hasta las últimas venas. ESCL. holoneural. CRIST. prismáticos grandes acompañando las venas y pequeñitos en el mesófilo.

MAT.EST. Madagascar. Humbert et Capuron 24233.

\section{B.humbertiana J.Ar. (sect. Vahihara)}

T. anisodictia. G. 3a. AR. reducidas, forma variable. VEN. frecuentes, simples o 
poco ramificadas, delgadas, formadas por una o dos filas de traqueidas espiraladas o escalariformes, a veces con elementos punteados. VAI. intermedia. EXT. parecen llegar hasta las venillas que cierran las aréolas. ESCL. polineural; elementos largos, de paredes gruesas, espiculados. CRIST. pocos cristales prismáticos a lo largo de las venas.

MAT.EST. Madagascar. Humbert 13767.

64. B.Idroboi Cristób. (sect. Vahihara)

T. anisodictia. G. 3a. AR. reducidas, forma variable. VEN. frecuentes, simples o poco ramificadas, formadas por varias filas de traqueidas espiraladas o escalariformes, a veces con elementos punteados en los extremos. VAI. intermedia. EXT. parecen existir solamente en las venas mayores y en las de mediano grosor. ESCL. polineural; elementos largos, delgados, de paredes gruesas, sin espículas. CRIST. no se observan.

MAT.EST. Colombia. Cuatrecasas 8962.

\section{B.implacabilis Cristób. (sect. Urticifolia)}

T. anisodictia. G. 4. AR. amplias, forma variable. VEN. frecuentes, robustas, simples o ramificadas, formadas por una a varias filas de traqueidas espiraladas, algunas veces escalariformes. VAI. parenquimática. EXT. presentes, excepto en las venillas que cierran las aréolas. ESCL. holoneural; elementos de longitud variable, con paredes gruesas, espiculadas. CRIST. no se observan.

MAT.EST. Brasil. Krapovickas et al. 23074.

\section{B.integrifolia Lace (sect. Vahihara)}

T. anisodictia. G. 2. AR. reducidas, forma variable. VEN. frecuentes, simples o poco ramificadas, robustas, formadas por dos o más filas de traqueidas espiraladas. Con frecuencia los extremos abultados formados por grupos de elementos. VAI. parenquimática. EXT. no llegan a las últimas venas. ESCL. oligoneural; elementos largos, delgados. CRIST. prismáticos en mesófilo y venas.

MAT.EST. China. Yunnan. Szemoa. Henry 13370 (NY).

\section{B.ivorensis Hallé (sect. Crassipetala)}

T. anisodictia. G. 3. AR. reducidas, forma variable. VEN. numerosas, simples o ramificadas, robustas, formadas por 1 o más filas de traqueidas espiraladas. VAI. parenquimática. EXT. faltan en las venas que delimitan aréolas. ESCL. polineural. CRIST. no se observan.

MAT.EST. Côte d'Ivoire. Pobéguin 231.

68. B.Jackiana: Wall. (sect. Vahihara)

T. isodictia. G. 7b. AR. muy reducidas, poligonales. VEN. muy escasas, forma- 
das sólo por células de la vaina. VAI. diferenciada. ESCL. polineural. EXT. en todas las venas excepto las más delgadas. CRIST. prismáticos acompañando las venas.

MAT.EST. Indonesia. Sumatra. Bandar Boeloeh. Asahan. Yates 2213 (UC).

\section{B.jaculifolia Pohl (sect. Byttneria)}

T. anisodictia. G. 4. AR. muy amplias y de forma variable, pero alargadas en la dirección del eje mayor de la hoja. VEN. frecuentes, robustas, simples a muy ramificadas, formadas por varias filas de traqueidas espiraladas; en los extremos hay grupos de elementos muy cortos, espiralados o escalariformes. VAI. parenquimática. EXT. faltan sólo en las venillas que delimitan las aréolas. ESCL. holoneural; fibroesclereidas con extremos retorcidos penetrando el mesófilo. En corte transversal las venas principales presentan, por encima y debajo del hacecillo dos cordones superpuestos de elementos esclerenquimáticos. CRIST. no se observan.

MAT.EST. Brasil. Irwin et al. 13900.

\section{B.lobata Baill. (sect. Vahihara)}

T. anisodictia. G. 4a. AR. reducidas, forma variable. VEN. frecuentes, delgadas, simples o bifurcadas, formadas por una o dos filas de traqueidas, frecuentemente con elementos punteados. VAI. intermedia. EXT. en las venas más delgadas hay solamente hacia la epidermis adaxial. ESCL. holoneural. CRIST. algunos prismáticos acompañando las venas.

MAT.EST. Madagascar. Hildebrandt 3170.

71. B.Lopez-Mirandae Cristób. (sect. Incasica)

T. anisodictia. G. 3a. AR. tamaño y forma variables. VEN. numerosas, simples o ramificadas, robustas, formadas por dos filas de traqueidas, con frecuencia más en los extremos; elementos traqueales espiralados o a veces escalariformes. VAI. intermedia. EXT. presentes excepto en las venillas últimas. ESCL. polineural; elementos largos, de paredes gruesas, espiculados. CRIST. algunas drusas contenidas en idioblastos de la vaina.

MAT.EST. Perú. Sagastegui 7587.

72. B.loxensis Cristób. (sect. Crassipetala)

T. anisodictia. G. 3. AR. tamaño y forma variables. VEN. numerosas, simples a muy ramificadas, robustas, formadas por una o dos filas de traqueidas espiraladas, a veces varias en los extremos, algunas escalariformes. VAI. parenquimática. EXT. presentes en las venas mayores. ESCL. polineural; elementos largos, de paredes gruesas. CRIST. no se observan.

MAT.EST. Ecuador. Espinosa 619. 


\section{B.lucida J.Ar. (sect. Vahihara)}

T. anisodictia. G. 4a. AR. reducidas, forma variable. VEN. frecuentes, simples o bifurcadas, formadas por una o dos filas de traqueidas espiraladas, a veces escalariformes, en muchos casos con elementos punteados. Con frecuencia los extremos son abultados, formados por grupos de elementos cortos. VAI. intermedia. EXT. no llegan a las venas que delimitan las arẻolas. ESCL. holoneural. CRIST. prismáticos grandes acompañando las venas y pequeños en el mesófilo. MAT.EST. Madagascar. Baron 6222.

\section{B.macrantha J.Ar. (sect. Vahihara)}

T. anisodictia. G. 3. AR. tamaño y forma variables. VEN. frecuentes, simples o ramificadas, formadas por una a varias filas de traqueidas espiraladas. A veces los extremos formados por grupos de elementos dilatados. VAI. parenquimática. A veces los elementos traqueales no se anastomosan directamente entre sí sino a través de la vaina. EXT. presentes en venas mayores y en muchas venas menores. ESCL. polineural; elementos largos y delgados. CRIST. no se observan.

MAT.EST. Madagascar. Andranomavo. Soalala. 10 XI 1958. Randriamiera 9728 (P).

\section{B.Mastersii Cristób. (sect. Vahihara)}

T. isodictia. G. 8. AR. muy reducidas, forma variable. VEN. muy escasas, simples, formadas por traqueidas espiraladas o solamente por elementos de la vaina. VAI. diferenciada; muchas de las últimas venas formadas solamente por células de la vaina, sin elementos espiralados. EXT. no llegan a las venillas que cierran las aréolas. ESCL. holoneural, con bracitos penetrando el mesófilo. CRIST. no se observan.

MAT.EST. Malasia. Maingay 241.

\section{B.melantha Mart. ex K.Schum. (sect. Crassipetala)}

T. anisodictia. G. 4a. AR. tamaño y forma variables. VEN. numerosas, simples o ramificadas, formadas por 1 a varias traqueidas espiraladas, o escalariformes, frecuentemente con elementos punteados en los extremos. VAI. intermedia. EXT. presentes en venas mayores y algunas venas de mediano grosor. ESCL. holoneural; elementos largos, de paredes gruesas, espiculados. CRIST. no se observan. MAT.EST. Perú. Kuhlman 1548.

\section{B.melastomaefolia St.Hil. (sect. Byttneria)}

T. anisodictia. G. 4. AR. amplias, forma variable. VEN. numerosas, simples o ramificadas, robustas, formadas por varias filas de traqueidas espiraladas o escalariformes, a veces con elementos punteados. VAI. parenquimática. EXT. presentes, faltan en las venillas que cierran las aréolas. ESCL. holoneural, con brazos libres en el mesófilo. CRIST. en el ejemplar 12061 hay drusas acompañando 
las venas.

MAT.EST. Brasil. Irwin et al. 12061 y 17244; Gregory, Krapovickas y Pietrarelli 9940.

78. B.Melleri Baker var. triloba J.Ar. (sect. Vahihara)

T. isodictia. G. 7b. AR. muy reducidas, forma generalmente poligonal. VEN. muy escasas, simples, formadas por una o dos filas de traqueidas espiraladas. VAI. diferenciada. ESCL. polineural. CRIST. prismáticos y drusas acompañando las venas. MAT.EST. Madagascar. Humbert 20381.

79. B.microphylla Jacq. (sect. Crassipetala)

T. anisodictia. G. 2. AR. relativamente amplias, forma irregular. VEN. numerosas, simples a muy ramificadas, frecuentemente con extremos abultados formados por una a varias traqueidas espiraladas. VAI. parenquimática. EXT. solamente en las venas más gruesas. ESCL. oligoneural. CRIST. priemáticos en abundancia, acompañando las venas hasta las vénulas.

MAT.EST. Jacquin s/n; Rep. Dominicana. Howard 8635.

\section{B.minytricha Cristób. (sect. Urticifalia)}

T. anisodictia. G. 1. AR. tamaño y forma variables. VEN. numerosas, generalmente ramificadas, robustas, formadas por una a varias filas de traqueidas espiraladas. VAI. parenquimática. ESCL. mononeural. CRIST. no se observan.

MAT.EST. Ecuador. André 4662.

\section{B.mollis H.B.K. (sect. Crassipetala)}

T. anisodictia. G. 4. AR. tamaño y forma variables. VEN. numerosas, simples a muy ramificadas, formadas por 1 ó 2 filas de traqueidas espiraladas, a veces más en los extremos. VAI. parenquimática. EXT. presentes en las venas mayores. ESCL. holoneural; elementos largos, espiculados, con algunos brazos penetrando el mesófilo. CRIST. no se observan.

MAT.EST. Colombia. Haught 6337.

\section{B.nitidula Baker (sect. Vahihara)}

T. anisodictia. G. 4a. AR. reducidas, forma generalmente poligonal. VEN. poco frecuentes, simples o ramificadas, robustas, formadas por 1 o dos filas de traqueidas espiraladas o escalariformes, muchas veces con elementos punteados. Con frecuencia los extremos abultados, formados por elementos cortos. VAI. intermedia. EXT. no llegan a las venillas que cierran las aréolas. ESCL. holoneural. CRIST. primáticos grandes y pequeños contenidos en células de la vaina.

MAT.EST. Madagascar. Baron 5886. 


\section{B.nossibeensis J.Ar. (sect. Vahihara)}

T. isodictia. G. 7. AR. reducidas, forma poligonal. VEN. escasas, simples, delgadas, formadas por una o dos filas de traqueidas espiraladas. VAI. parenquimática. ESCL. polineural; elementos largos, paredes no muy gruesas. CRIST. no se observan.

MAT.EST. Madagascar. Vallée de Sambirano. IV 1924. Perrier 16091 (P).

\section{B.obliqua Benth. (sect. Crassipetala)}

T. anisodictia. G. 4. AR. relativamente amplias, de forma variable. VEN. frecuentes, simples o ramificadas, formadas por una a varias filas de traqueidas espiraladas o escalariformes. VAI. parenquimática; en el ejemplar 8176 es de tipo intermedio. EXT. presentes excepto sobre las venas más pequeñas. ESCL. holoneural; fibroesclereidas largas, de paredes gruesas, con extremos retorcidos libres en el mesófilo. CRIST. algunos cristales prismáticos acompañando las venas.

MAT.EST. Brasil. Prance et al. 8176; Manaus. Igarapé de São Raimundo. 23 I 1956. Chagas s/n (CTES); Rodríguez y Lima 2243; Rodríguez y Coelho 1648; Ducke 1904.

\section{B.oblongata Pohl (sect. Byttneria)}

T. anisodictia. G. 4. AR. amplias, forma muy variable. VEN. frecuentes, simples o ramificadas, formadas por 1 a varias filas de traqueidas espiraladas. A veces los extremos presentan grupos de elementos cortos y dilatados, espiralados o escalariformes. VAI. parenquimática. EXT. faltan sólo en las últimas venas. ESCL. holoneural; fibroesclereidas de paredes gruesas, extremos retorcidos penetrando el mesófilo. CRIST. prismáticos acompañando las venas mayores.

MAT.EST. Argentina. Krapovickas et al. 14039.

\section{B.oblongifolia J.Ar. (sect. Vahihara)}

T. isodictia. G. 7b. AR. reducidas. VEN. escasas, simples, generalmente formadas solamente por elementos de la vaina. VAI. diferenciada. ESCL. polineural. CRIST. prismáticos, en mesófilo y a lo largo de las venas.

MAT.EST. Madagascar. Perrier 12641.

\section{B.obtusata Benth. ex Hochr. (sect. Incasica)}

T. anisodictia. G. 4a. AR. reducidas, forma variable. VEN. numerosas, simples o ramificadas, robustas, formadas por 1 o dos filas de traqueidas espiraladas, a veces con elementos punteados. VAI. intermedia. ESCL. holoneural; elementos de longitud variable con paredes gruesas, espiculadas. CRIST. drusas acompañando las venas.

MAT.EST. Ecuador. Spruce 6024. 
88. B.oligantha J.Ar. (sect. Vahihara)

T. anisodictia. G. 2. AR. relativamente amplias, forma variable. VEN. frecuentes, simples o poco ramificadas, robustas, formadas por dos o más filas de traqueidas espiraladas, a veces más en los extremos. VAI. parenquimática. ESCL. oligoneural. CRIST. numerosos cristales prismáticos acompañando las venas y en el mesófilo.

MAT.EST. Madagascar. Humbert 20088.

\section{B.oranensis Cristób. (sect. Vahihara)}

T. isodictia. G. 6. AR. relativamente amplias, forma poligonal. VEN. escasas, simples o excepcionalmente bifurcadas, formadas por dos o más filas de traqueidas espiraladas. VAI. parenquimática. EXT. presentes en venas mayores y algunas de grosor mediano. ESCL. oligoneural. CRIST. no se observan. MAT.EST. Argentina. Cristóbal 650.

\section{B.Ostenii Cristób. (sect. Urticifolia)}

T. anisodictia. G. 2. AR. amplias, forma variable. VEN. numerosas, simples o ramificadas, formadas por una o dos filas de traqueidas espiraladas. VAI. parenquimática. ESCL. oligoneural; elementos largos, de paredes gruesas. CRIST. numerosísimas drusas acompañando las venas.

MAT.EST. Paraguay. Hassler 12145.

\section{B.ovata Lam. (sect. Incasica)}

T. anisodictia. G. 2. AR. tamaño y forma variables. VEN. numerosas, simples a muy ramificadas, formadas por dos o más filas de traqueidas espiraladas, algunas escalariformes. Muchas veces los extremos formados por elementos dilatados. VAI. parenquimática. EXT. presentes, excepto en algunas venas muy pequeñas; algunas venas poseen extensiones sólo hacia la epidermis adaxial. ESCL. oligoneural. CRIST. algunas drusas acompañando las venas.

MAT.EST. Ecuador. Quito. Base del Pichincha (LIL 144903); Acosta Solís 8124.

\section{B.ovatifolia J.Ar. (sect. Vahihara)}

T. anisodictia. G. 3a. AR. reducidas, forma variable. VEN. frecuentes, delgadas, simples o ramificadas, formadas por una o dos filas de traqueidas espiraladas o escalariformes, a veces con elementos punteados. A veces hay traqueidas dilatadas en los extremos. VAI. intermedia; algunas de las últimas venas carecen de elementos traqueales espiralados. EXT. presentes, aunque no llegan a las venas menores. ESCL. polineural; elementos largos y delgados. CRIST. no se observan. MAT.EST. Madagascar. Decary 2297.

\section{B.palustris Cristób. (sect. Byttneria)}

T. anisodictia. G. 4. AR. tamaño y forma variables. VEN. numerosas, simples o 
ramificadas, robustas, formadas por varias filas de traqueidas espiraladas o escalariformes. Muchas veces hay en los extremos grupos de elementos cortos y dilatados, generalmente espiralados. VAI. parenquimática. EXT. faltan sólo en las venas menores. ESCL. holoneural; fibroesclereidas largas, de paredes gruesas, cuyos extremos penetran el mesófilo. CRIST. drusas acompañando las venas.

MAT.EST. Brasil. Hatschbach y Guimarães 24269.

\section{B.parviflora Benth. (sect.Incasica)}

T. anisodictia. G. 2. AR. reducidas, forma variable. VEN. frecuentes, simples o ramificadas, formadas por una a varias traqueidas espiraladas. Muchas veces los extremos formados por elementos cortos, ocasionalmente dilatados. VAI. parenquimática. EXT. parecen faltar solamente en algunas de las últimas venillas. ESCL. oligoneural; elementos largos, delgados. CRIST. numerosas drusas acompañando las venas.

MAT.EST. Ecuador. Schimpff 1044.

\section{B.Pedersenii Cristób. (sect. Byttneria)}

T. anisodictia. G. 4. AR. muy amplias, forma muy variable. VEN. numerosas, robustas, generalmente ramificadas, formadas por una a varias traqueidas espiraladas. Muchas veces en los extremos hay grupos de elementos cortos y dilatados. VAI. parenquimática. EXT. presentes excepto en las venillas que cierran las aréolas. ESCL. holoneural; fibroesclereidas de paredes gruesas cuyos extremos penetran el mesófilo. CRIST. no se observan.

MAT.EST. Argentina. Krapovickas y Cristóbal 12118.

\section{B.Perrieri Hochr. var. Decaryana J.Ar. (sect. Vahihara)}

T. isodictia. G. 7a. AR. reducidas, poligonales. VEN. escasas, generalmente simples, formadas por 1 ó 2 filas de traqueidas espiraladas, a veces escalariformes. VAI. intermedia. EXT. presentes excepto en las venas más delgadas. ESCL. polineural; elementos largos, delgados, de paredes no muy gruesas. CRIST. prismáticos grandes acompañando las venas, pequeños en el mesófilo.

MAT.EST. Madagascar. Decary 1589.

97. B.pescapraeifolia Britt. (sect. Vahihara)

T. isodictia. G. 6b. AR. muy reducidas, forma poligonal. VEN. muy escasas, simples, formadas por traqueidas espiraladas o solamente por elementos de la vaina. VAI. diferenciada. EXT. faltan solamente en algunas de las últimas venillas. ESCL. oligoneural. CRIST. no se observan.

MAT.EST. Brasil. Krukoff 5751.

98. B.petiolata Cristób. (sect. Byttneria)

T. anisodictia. G. 4. AR. amplias, forma muy variable. VEN. numerosas, robus- 
tas, simples a muy ramificadas, formadas por una a varias filas de traqueidas espiraladas o escalariformes, a veces con elementos punteados. Frecuentemente se observan grupos de elementos cortos en los extremos. EXT. faltan solamente en las venillas más delgadas. ESCL. holoneural; elementos de fórma variable, paredes gruesas, con numerosos brazos penetrando el mesófilo. CRIST. drusas acompañando las venas.

MAT.EST. Brasil. Irwin et al. 16316.

\section{B.pilosa Roxb. (sect. Vahihara)}

T. anisodictia. G. 2. AR. tamaño y forma variables. VEN. poco frecuentes, simples o bifurcadas, formadas por una o dos filas de traqueidas espiraladas, a veces con elementos punteados. VAI. parenquimática. ESCL. oligoneural. CRIST. prismáticos junto a las venas mayores.

MAT.EST. Vietnam. Annam. Prov. du Haut-Donnaî. 8 VIII 1934. Poilane 23365 (UC).

\section{B.Piresii Cristób. (sect. Vahihara)}

T. isodictia. G. 8. AR. muy reducidas, poligonales. VEN. escasas, delgadas, generalmente simples y formadas sólo por células de la vaina. VAI. diferenciada; algunas de las últimas venas carecen dẽ elementos traqueales espiralados. EXT. presentes en las venas mayores. ESCL. holoneural; con bracitos penetrando el mesófilo. CRIST. no se observan.

MAT.EST. Brasil. Rodríguez 79.

\section{B.ramosissima Pohl (sect. Byttneria)}

T. anisodictia. G. 4. AR. muy amplias y de forma variable. VEN. simples a muy ramificadas, numerosas, robustas, formadas por una a varias filas de traqueidas espiraladas; en muchos extremos se encuentran grupos de elementos cortos. VAI. parenquimática. EXT. faltan solamente en las venillas que cierran las aréolas. ESCL. holoneural; fibroesclereidas largas, con extremos retorcidos penetrando el mesófilo. CRIST. no se observan.

MAT.EST. Paraguay. Krapovickas et al. 12321.

\section{B.Reinwardtii Korth. (sect. Vahihara)}

T. isodictia. G. 7a. AR. muy reducidas. VEN. muy escasas, formadas por elementos de la vaina. Algunas de las últimas venas sin elementos traqueales espiralados. VAI. intermedia. EXT. presentes excepto en las últimas venillas. Algunas venas sólo poseen extensiones hacia la epidermis abaxial. ESCL. polineural. CRIST. muchísimos cristales prismáticos en el mesófilo y acompañando las venas.

MAT.EST. Malasia. Borneo. Tawao. Elphinstone Prov. X 1922- III 1923. Elmer 21697 (MO). 


\section{B.rhamnifolia Benth. (sect. Urticifolia)}

T. anisodictia. G. 4a. AR. reducidas, en el ejemplar 267 relativamente amplias. Forma variable. VEN. numerosas, simples o ramificadas, formadas por una o dos filas de traqueidas espiraladas, a veces más en los extremos; ocasionalmente presentan elementos punteados. VAI. intermedia. EXT. presentes excepto en las venillas que delimitan las aréolas. ESCL. holoneural; fibroesclereidas de forma, tamaño y densidad variable, acompañando las venas e invadiendo el mesófilo. CRIST. prismáticos acompañando las venas, en el ejemplar 4236 hay también en el mesófilo; en los ejemplares 3992, 4690 y 192 no se observan. OBS. los ejemplares de Argentina, Bolivia, Brasil y Paraguay presentan estomas en ambas epidermis, en tanto que los ejemplares de Colombia y Venezuela los presentan principalmente en la epidermis abaxial.

MAT.EST. Argentina. Krapovickas y Cristóbal 11356, 11358, 11361, 12721 y 20061; Rojas 11867. Bolivia. Werdermann 2423; Scolnik y Luti 659; O. Kuntze s/n; Brasil. Spruce 167 y 267; Moore 1015; Malme s/n; Hoehne 4236; O.Kuntze s/n; Paraguay. Meyer 16145; Colombia. Cuatrecasas 3992; Bond 192; Gutierrez 813; Venezuela. Vélez 2234; Aristeguieta 4690; Rusby 258; Badillo 1273.

\section{B.rubriflora J.Ar. (sect. Vahihara)}

T. isodictia. G. 5. AR. muy reducidas. VEN. simples, escasas, formadas por una o dos filas de traqueidas espiraladas. VAI. parenquimática; muchas veces los elementos traqueales no se anastomosan directamente entre sí, sino a través de la vaina. EXT. parecen estar presentes en todas las venas, excepto algunas de las venillas que cierran aréolas. ESCL. mononeural. CRIST. algunas drusas contenidas en idioblastos de la vaina.

MAT.EST. Madagascar. Perrier 1146.

\section{B.sagittifolia St.Hil. (sect. Byttneria)}

T. anisodictia. G. 4. AR. relativamente amplias, forma variable. VEN. numerosas, simples o ramificadas, robustas, formadas por una a varias filas de traqueidas espiraladas, a veces escalariformes, ocasionalmente con elementos punteados. Los extremos presentan con frecuencia grupos de elementos cortos. VAI. parenquimática. EXT. faltan sólo en las venillas que cierran las aréolas. ESCL. holoneural; fibroesclereidas cuyos extremos retorcidos penetran el mesófilo. CRIST. en el ejemplar 9641 hay drusas acompañando las venas.

MAT.EST. Brasil. São Paulo. Mojí-Guaçú. Perto de Padua Sales. Fazenda Campininha. 30 X 1957. Handro 716 (SP); Mattos 9641.

106. B.sambiranensis J.Ar. (sect. Vahihara)

T. isodictia. G. 7a. AR. reducidas, forma poligonal. VEN. escasas, simples o a veces bifurcadas, formadas por traqueidas espiraladas o escalariformes, algunas 
veces sólo por elementos de la vaina. Frecuentemente los extremos formados por elementos dilatados. VAI. intermedia. EXT. parecen existir en las venas mayores. ESCL. polineural; elementos cortos, de paredes gruesas, espiculados, con puntuaciones simples. CRIST. no se observan.

MAT.EST. Madagascar. Decary 1075.

\section{B.scabra L. (sect. Byttneria)}

T. anisodictia. G. 4. AR. amplias, de forma muy variable. VEN. numerosas, simples o ramificadas, robustas, formadas por una o dos filas de traqueidas espiraladas o escalariformes; muchas veces en los extremos hay grupos de elementos cortos. VAI. parenquimática. EXT. presentes excepto en las venillas que cierran las aréolas. ESCL. holoneural; fibroesclereidas largas, con extremos retorcidos penetrando el mesófilo. CRIST. el ejemplar 12120 presenta drusas acompañando las venas. OBS. mesófilo de estructura dorsiventral.

MAT.EST. Argentina. Krapovickas y Cristóbal 12050; Corrientes. Capital. Cultivado Facultad de Agronomía y Veterinaria, proc. de Costa Toledo, Corrientes. Krapovickas y Cristóbal 12120 (CTES).

108. B.scabrida Ridley (sect. Vahihara)

T. isodictia. G. 7a. AR. reducidas, forma variable. VEN. escasas, simples o bifurcadas, formadas por una a varias filas de traqueidas esptraladas. VAI. intermedia. ESCL. polineural. CRIST. prismáticos y algunas drusas, en células de la vaina.

MAT.EST. Malasia. Sarawak. Borneo. Gat, upper Rejang river. 1929. Clemens 21524 (P).

109. B.scalpellata Pohl (sect. Byttneria)

T. anisodictia. G. 4. AR. amplias, de forma muy variable. VEN. numerosas, robustas, simples o ramificadas, formadas por dos o más filas de traqueidas espiraladas o escalariformes. En los extremos hay grupos de elementos cortos, a veces dilatados. VAI. parenquimática. EXT. presentes excepto en las venillas que cierran las aréolas. ESCL. holoneural; fibroesclereidas de paredes gruesas cuyos extremos penetran el mesófilo. CRIST. el ejemplar 13537 presenta drusas acompañando las venas.

MAT.EST. Brasil. Irwin et al. 11595 y 13537.

\section{B.Sparrei Cristób. (sect. Incasica)}

T. anisodictia. G. 3. AR. tamaño y forma variables. VEN. numerosas, simples o ramificadas, formadas por una a varias filas de traqueidas espiraladas. A veces con elementos dilatados en los extremos. VAI. parenquimática, con idioblastos conteniendo cristales. EXT. no existen en las venas menores. ESCL. polineural. 
CRIST. drusas acompañando las venas. MAT.EST. Ecuador. Sparre 16117.

\section{B.stenophylla Cristób. (sect. Byttneria)}

T. anisodictia. G. 4. AR. generalmente amplias, de forma variable. VEN. numerosas, simples o ramificadas, robustas, formadas por varias filas de traqueidas espiraladas o escalariformes; en algunos casos los extremos dilatados, formados por grupos de traqueidas. VAI. parenquimática. EXT. presentes excepto en las venillas que cierran las aréolas. ESCL. holoneural, con brazos libres en el mesófilo. CRIST. no se observan.

MAT.EST. Paraguay. Krapovickas et al. 14004 y 14253.

\section{B.subsessilis Cristób. (sect. Byttneria)}

T. anisodictia. G. 4. AR. amplias generalmente, forma muy variable. VEN. numerosas, simples o ramificadas, formadas por una a varias filas de traqueidas espiraladas. Frecuentemente se observan los extremos dilatados formados por grupos de traqueidas cortas, espiraladas o escalariformes. VAI. parenquimática. EXT. presentes excepto en las venas que delimitan las aréolas. ESCL. holoneural, con algunos brazos libres en el mesófilo. CRIST. prismáticos, acompañando las venas. MAT.EST. Paraguay. Krapovickas et al. 13953 y 14181.

\section{B.tortilis Gagnep. (sect. Vahihara)}

T. anisodictia. G. 3. AR. reducidas, VEN. frecuentes, simples o bifurcadas, delgadas, formadas por una o dos filas de traqueidas espiraladas, algunas escalariformes. VAI. parenquimática. ESCL. polineural; elementos largos, delgados. CRIST. prismáticos grandes, siguiendo las venas.

MAT.EST. Laos. Thorel 2330.

\section{B.triadenia Cristób. (sect. Urticifolia)}

T. anisodictia. G. 4. AR. forma y tamaño variables. VEN. numerosas, simples o ramificadas, robustas, formadas por una a varias filas de traqueidas espiraladas o escalariformes, a veces con elementos dilatados en los extremos. VAI. parenquimática. ESCL. holoneural; elementos largos, de pared gruesa, espiculados. CRIST. drusas en abundancia, siguiendo las venas.

MAT.EST. Brasil. Sta. Catharina. 30 XII 1882. Capanema s/n.

\section{B.tucumanensis Cristób. (sect. Urticifolia)}

T. anisodictia. G. 1. AR. tamaño variable, forma generalmente poligonal. VEN. numerosas, simples o ramificadas, formadas por una o dos filas de traqueidas espiraladas. VAI. parenquimática. EXT. no hay en las venas más delgadas. ESCL. mononeural. CRIST. drusas acompañando las venas.

MAT.EST. Argentina. Arbo 117. 


\section{B.uaupensis Spruce ex K.Schum. (sect. Vahihara)}

T. isodictia. G. 7a. AR. muy reducidas, forma poligonal. VEN. muy escasas, simples, robustas, formadas por traqueidas espiraladas, escalariformes o sólo por elementos de la vaina. VAI. muy diferenciada, especialmente en el ejemplar 2863. EXT. presentes en las venas más gruesas. Las venas de grosor mediano poseen extensiones pero no hasta la epidermis. ESCL. polineural. CRIST. prismáticos acompañando las venas, también en el mesófilo en los ejemplares 2466 y 2863.

MAT.EST. Colombia. Cuatrecasas 7207; Brasil. Spruce 2466; Guayana Británica. Smith 2863.

\section{B.urosepala Mildbr. (sect. Urticifolia)}

T. anisodictia. G. 4a. AR. tamaño y forma variables. VEN. numerosas, robustas, simples o ramificadas, formadas por una a varias filas de traqueidas espiraladas y células esclerificadas cortas. VAI. diferenciada, se confunde con el esclerénquima. EXT. no hay sobre las venillas últimas. ESCL. elementos esclerenquimáticos de longitud variable, largos en las venas mayores y cortos en las menores y vénulas. Paredes muy gruesas, con numerosas puntuaciones simples. Estrictamente holoneural. CRIST. no se observan.

MAT.EST. Perú. Sandeman 4467.

\section{B.urticifolia K.Schum. (sect. Urticifolia)}

T. anisodictia. G. 2. AR. forma variable, amplias. VEN. numerosas, simples o ramificadas, formadas por una o dos filas de traqueidas espiraladas, a veces más en los extremos, ocasionalmente con elementos punteados. VAI. parenquimática. EXT. presentes, aunque no llegan a las venas más delgadas. ESCL. oligoneural; elementos largos, de pared gruesa. CRIST. drusas en abundancia a lo largo de las venas.

MAT.EST. Argentina. Corrientes. Cult. Facultad de Agronomía y Veterinaria, proc. de Arroyo San Juan, Misiones. 6 III 1967. Arbo 33 (CTES); Krapovickas y Cristóbal 12049 y 11390.

\section{B.Vargasii Cristób. (sect. Incasica)}

T. anisodictia. G. 3. AR. tamaño y forma variables. VEN. numerosas, delgadas, simples y ramificadas, formadas por 1 ó 2 filas de traqueidas espiraladas. VAI. parenquimática, con algunos idioblastos conteniendo cristales. EXT. no hay en las venas menores. ESCL. polineural, elementos largos, delgados. CRIST. drusas a lo largo de las venas.

MAT.EST. Perú. Vargas 9736.

\section{B.vitifolia Baill. (sect. Vahihara)}

T. isodictia. G. 7a. AR. reducidas, forma generalmente poligonal. VEN. escasas, 
simples o a veces bifurcadas, formadas por 1 a varias filas de traqueidas espiraladas. VAI. intermedia. EXT. presentes, aunque no llegan a las venas más pequeñas. ESCL. polineural; elementos largos, delgados. CRIST. prismáticos, a lo largo de las venas y en el mesófilo.

MAT.EST. Madagascar. Boivin 2137.

\section{B.voulily Baill. (sect. Vahihara)}

T. isodictia. G. 7a. AR. reducidas, forma generalmente poligonal. VEN. escasas, simples o excepcionalmente bifurcadas, formadas por una o dos filas de traqueidas espiraladas o escalariformes, algunas veces con elementos punteados. VAI. intermedia. EXT. presentes aunque no llegan a las venas más delgadas. ESCL. polineural; elementos largos, delgados, de paredes gruesas. CRIST. no se observan. MAT.EST. Madagascar. Antsalova. 11 XII 1958. Res.Nat.Madag. 10312 (P).

\section{B.Weberbaueri Mildbr. (sect. Incasica)}

T. anisodictia. G. 3a. AR. amplias, forma variable. VEN. numerosas, simples a muy ramificadas, robustas, formadas por una a varias filas de traqueidas espiraladas, algunas escalariformes. VAI. intermedia. EXT. presentes en las venas mayores y algunas de grosor mediano; contienen bolsas de mucílago. ESCL. polineural; elementos largos, de paredes no muy gruesas. CRIST. no se observan. MAT.EST. Perú. Stork et Horton 10038.

\section{Bibliografía (1)}

Albuquerque, B.W.P. 1972. Contribuiçao ao estudo da nervaçao foliar de plantas da flora amazónica. Acta Amazonica 2 (1): 21-28.

Arens, K. 1958. Consideraçoes sobre as causas do xeromorfismo foliar. Bol.Fac. Filos.Univ. São Paulo, Bot. 15: 25-56.

Armacost. R.R. 1944. The structure and junction of the border parenchyma and vein-ribs of certain dicotyledon leaves. Proc.lowa Acad.Sci. 51: 157-169.

Bailey, I.W. and Nast. C.G. 1944. The comparative morphology of the Winteraceae. IV. Anatomy of the node and vascularization of the leaf. J.Arnold Arbor. 25: 215-220.

- 1944. The comparative anatomy of the Winteraceae. V. Foliar epidermis

(1) Los trabajos que no consulté personalmente están marcados con un asterisco.

Tomé las abreviaturas de las publicaciones de Lawrence, G.H.M. et al. 1968. BotanicoPeriodicum-Huntianum. Pittsburg. 
and sclerenchima. J.Arnold Arbor. 25: 342-348.

Carlquist, S. 1957. Leaf anatomy and ontogeny in Argyroxiphium and Wilkesia (Compositae). Amer. J. Bot. 44: 696-705.

- 1958. Anatomy of Gauyana Mutisieae. Part. II. Mem. New York Bot. Gard. 10: $157-184$.

- 1959 a. Vegetative anatomy of Dubautia, Argyroxiphium and Wilkesia (Compositae). Pacific. Sci. 13: 195-210.

- 1961. Comparative plant anatomy. New York. Holt, Rinehart, Winston.

Chacur, F. 1968. Contribuiçao ao estudo da nervaçao foliar de plantas dos Cerrados. Acanthaceae, Anonaceae, Anacardiaceae. Arq. Bot. Estado São Paulo 4 (3): 141-152.

Dames e Silva, J. 1973. Catálogo de nervaçao foliar das Anacardiaceae da Caatinga. I. Arch.Jard.Bot. Rio de Janeiro 39: 249-256.

*De Vries, H. 1879. Beitrage zur speciellen Physiologie Landwirts chaftlicher Culturpflanzen. Wachstumsgeschichte der Zuckerrube. Landw.Jahrb. 8:417 499.

Dehay, Ch. 1939. L'appareil libero-ligneux foliaire des Sterculiacées. Ann.Sci.Nat. Bot.Serie 11 - 1: 45-131.

Dilcher, D.L. 1974. Approaches to the identification of Angiosperm leaf remains. Bot.Rev.(Lancaster) 40(1): 1-157.

Eames, A.J. and Mac Daniels, L.H. 1947. An introduction to plant anatomy.Mc. Graw. New York.

Esau, K. 1965. Plant Anatomy. 2nd. edition. J.Wiley and sons. New York.

Felippe, G.M. y Magalhaes,F.M. 1966. Contribuiçao ao estudo da nervaçao foliar das Compositae dos Cerrados. I. Tribus Helenieae, Heliantheae, Inuleae, Mutisieae e Senecioneae. II Simposio sobre o Cerrado. Anais Acad. Brasil. Ci. 38: 125-157, 132 fig.

Ferreira, A.G. 1968. Contribuiçao ao estudo da nervaçao foliar das Compositae dos Cerrados. IV. Tribo Eupatorieae. Arq.Bot.Estado São Paulo 4. (3): 153-170.

Ferreira de Carvalho, L.D. y Valente, M.C. 1973. Contribuiçao ao estudo da nervaçao foliar das Leguminosae dos cerrados. III. Faboideae. Tribu Phaseoleae. Arch.Jard.Bot. Rio de Janeiro 19: 227-248.

Ferri, M.G. 1944. Transpiraçao de plantas permanentes dos cerrados. Bol.Fac. Filos.Univ.São Paulo 41, Bot. 4: 159-224.

*Fischer, A. 1885. Studien über die Siebröhnen der Dicotylenblätter. Verh.Königl.Sächs.Ges.Wiss.Leipzig, Math.-Phys.Cl. 37: 245-290.

Foster, A.S. 1949. Practical Plant Anatomy. 2nd. ed. D.Van Nostrand Comp. Inc. New York.

- 1950a. Morphology and venation of the leaf in Quiina acutangula Ducke. Amer. J. Bot. 37: 159-171. 
- $1950 \mathrm{~b}$. Venation and histology of the leaflets in Touroulia guianensis Aubl. and Froesia tricarpa Pires. Amer. J. Bot. 37 (10): 848-864.

- 1951. Heterophylly and foliar venation in Lacunaria. Bull. Torrey Bot. Club 78: 382 - 400 .

- 1952. Foliar venation in angiosperms from an ontogenetic stand point. Amer.J.Bot. 39: 752-766.

- 1966. Mor̀̀hology of anastomosis in the dichotomous venation of Circaeaster. Amer.J.Bot. 53(6): 588-599.

Fraga, W., Magalhaes, F. y Lima Correia F. 1973. Notas sobre a anatomía e morfología da especie Polygala paniculata L. Arch. Jard. Bot. Rio de Janeiro 39: 281-294.

Freire de Carvalho, L. 1967. Contribuiçao ao estudo da nervaçao foliar das Leguminosae dos cerrados. Anais Acad.Brasil.Ci. 39 (34): 507-520.

- 1970. Contribuiçao ao estudo da nervaçao foliar das Leguminosae dos Cerrados. II. Mimosoideae. Anais Acad. Brasil. Ci 42(1): 79-88.

*Haberlandt, G. 1882. Vergleichende Anatomie des assimilatorischen Gewebesystems der Pflanzen. Jahrb.Wiss.Bot. 13: 74-188.

Handro, W. 1964. Contribuiçao ao estudo da venaçao e anatomía foliar das $\mathrm{Ama}$ rantaceae dos Cerrados. Anais Acad. Brasil.Ci. 36(4): 479-499.

- 1966. Escleromorfismo foliar e nutriçao mineral em Gomphrena prostrata Mart. II Simposio sobre o Cerrado. Anais Acad. Brasil. Ci. 38.

- 1967. Contribuiçao ao estudo da venaçao e anatomía foliar das Amarantaceae dos Cerrados. II. Genero Pfaffia. Anais Acad.Brasil.Ci. 39 (34): 495-506.

Hanson, H.C. 1917. Leaf structure as related to environment. Amer. J. Bot. 4: $533-560$.

*Heinricher, E. 1886. Ueber einige im Laube dicotyler Pflanzentrockenen Standortes auftretende Einrichtungen, \&c. Bot.Centralb. 23.

Hickey, L.J. 1974. Clasificación de la arquitectura de las hojas de dicotiledóneas. Bol.Soc.Argent.Bot. 16 (1-2): 1-26. Artículo publicado en Amer.J.Bot. 60 (1): 17-33, 1973, traducido por E.M.Zardini.

Isebrands, J.G. and Larson,P.R. 1973. Anatomical changes during leaf ontogeny in Populus deltoides. Amer.J.Bot. 60: 199-208.

Kapoor, S.L., Sharma P.C., Chandra, V. y Kapoor, L.D. 1969. Epidermal and venation studies in Apocynaceae. II. Bull.Bot.Surv.India 11 (3-4): 372-376.

Laroche, R.C. 1973. Catálogo de Nervaçao foliar das Amaranthaceae e Annonaceae da caatinga: III. Arch.Jard.Bot.Rio de Janeiro 39: 269-280.

Metcalfe, C.R. and Chalk, L. 1950. Anatomy of the dicotyledons. Oxford: Clarendon Press.

Morretes, B.L. 1966a. Contribuiçao ao estudo da anatomía das folhas de plantas do Cerrado, II. Bol.Fac.Filos.Univ.Sao Paulo Bot. 22: 209-244. 
- 1966 b. Floema terminal em feixes vasculares do mesófilo de Syringa vulgaris e Boerhaavia coccinea. Bol.Fac.Filos.Univ.Sao Paulo Bot. 22: 293-312. Morretes, B.L. and Ferri,'M.G. 1959. Contribuiçao ao estudo da anatomía das folhas de plantas do cerrado. Bol.Fac.Filos.Univ.Sao Paulo Bot. 16: 1-70.

Mouton, J.A. 1966. Sur la systematique foliaire en paléobotanique. Bull.Soc.Bot. France 113 (9): 492-502.

- 1972. Contribution de la morphologie foliaire a la Phylogenie des angiospermes. Comptes rendus du $93^{\circ}$ congreso nac. des societés savantes. Section des sciences, 3: 199-209.

Napp-Zinn, K. 1973-74. Anatomie des Blattes. II Angiospermen en Linsbauer et al. Handbuch der Pflanzenanatomie VIII (2). Berlin. Gebrüder Borntraeger. Paula, J. 1966. Contribuiçao ao estudo da nervaçao foliar das compostas dos Cerrados. III: Tribo Astereae. Bol. Mus. Paraense Emilio Goeldi Nov. Sér. Bot. 23: 1-13, 73 fig.

- 1967 a. Estudos sobre Vochysiaceae. I. Contribuiçao ao conhecimento da morfología foliar de Erisma uncinatum Warming, E. calcaratum (Link) Warming e E.splendens Stafleu, da Amazonia. Bol.Mus.Paraense Emilio Goeldi Nov. Ser. Bot. 27: 1-12.

- 1967 b. Estudos sobre Vochysiaceae. II. Contribuiçao para o conhecimento dos generos Erisma Rudge e Qualea Aublet. Bol. Mus. Paraense Emilio Goeldi Bot. 28: 1-9.

- 1967 c. Estudos sobre Vochysiaceae. III. Contribuiçao ao conhecimento de Erisma bicolor Ducke e E.macrophyllum Ducke. Bol. Mus.Paraense Emilio Goeldi Bot. 29.

Philpott, J. 1953. A blade tissue study of leaves of forty seven species of $\mathrm{Fi}$ cus. Bot.Gaz.(Crawfordsville) 115: 15-35.

- 1956. Blade tissue organization of foliage leaves of some Carolina shrubbog species as compared with their Appalachian mountain affinities. Bot. Gaz.(Crawfordsville) 118: 88-105.

Pirwitz, K. 1931. Physiologische und anatomische Untersuchungen an Speichertracheiden und Velamina. Planta 14: 19-76.

Plymale, E.L. and Wylie,R.B. 1944. The major veins of mesomorphic leaves. Amer.J.Bot. 31: 99-106.

Pray, T.R. 1954. Foliar venation of angiosperms. I. Mature venation of Liriodendron. Amer.J.Bot. 41: 663-670.

- 1955a. Foliar venation of angiosperms. II. Histogenesis of the venation in Liriodendron. Amer.J.Bot. 42: 18-27.

1955b. Foliar venation of angiosperms. III. Pattern and histology of the venation of Hosta. Amer.J.Bot. 42: 611-618.

- 1955c. Foliar venation of angiosperms. IV. Histogenesis of the venation of Hosta. Amer.J.Bot. 42: 698-706. 
- 1963. Origin of vein endings in angiosperm leaves. Phytomorphology 13: 60-81.

Ryder, V.L. 1954. On the morphology of leaves. Bot.Rev.(Lancaster) 20: 263-270.

${ }^{*}$ Schubert, B. 1897. Ueber die Parenchumscheiden in den Blattern der Dicotylen. Bot.Centralbl. 71 (37): 385-395; 72 (40): 13-21; 72 (41): $61-69$.

Shields, L.M. 1950. Leaf xeromorphy as related to physiological and structural influences. Bot.Rev. (Lancaster) 16: 399447.

Silva, M.F. 1968. Estudos sobre Caryocaraceae. I. Contribuiçao para o conhecimento da morfología foliar de Caryocar glabrum (Aubl.) Pers. e Caryocar microcaryum Ducke, da Amazonia. Bol.Inst.Nac.Pesq.Amazonia Bot. 28.

- 1969. Estudos sobre Caryocaraceae. II. Contribuiçao para o conhecimento da morfología foliar de Caryocar villosum (Aubl.) Pers. e Caryocar pallidum A.C.Smith, da Amazonia. Bol.Inst.Nac.Pesq. Amazonia Bot. 29: 1.16.

Slade, B.F. 1957. Leaf development in relation to venation as shown in Cercis siliquastrum L., Prunus serrulata Lindl., and Acer pseudoplatanus L. New Phytol. 56: 281-300.

Strain, R.W. 1933. A study of vein endings in leaves. Amer.Midl.Naturalist 14: 367-375.

Takeda, H. 1913. A theory of transfusion tissue. Ann.Bot.(London) 27: 359-363.

Valente, M.C. 1973. Catálogo da nervaçao foliar das Apocynaceae da caatinga. II. Arch. Jard. Bot. Río de Janeiro 39: 257-268.

Wylie, R.B. 1938. Concerning the conductive capacity of the minor veins of foliage leaves. Amer.J.Bot. 25: 567-572.

- 1939. Relations $b_{w^{\prime}}$ tween tissue organization and vein distribution in dicotyledon leaves. Amer.J.Bot. 26: 219-225.

- 1943. The role of the epidermis in foliar organization and its relations to the minor venation. Amer.J.Bot. 30: 273-280.

- 1946a. Conduction in dicotyledon leaves. Proc.Iowa Acad.Sci. 53: 195-202.

- $1946 \mathrm{~b}$. Relations between tissue organization and vascularization in leaves of certain tropical and subtropical dicotyledons. Amer.J.Bot. 33: 721-726.

- 1951. Principles of foliar organization shown by sun-shade leaves from 10 sp of deciduous dicotyledon trees. Amer.J.Bot. 38: 355-361.

- 1952. The bundle sheath extension in leaves of dicotyledons. Amer.J.Bot. 39: 645-651.

- 1954. Leaf organization of some woody dicotyledons from New Zealand. Amer.J.Bot. 41: 186-191.

Yarbrough, J. 1934. History of leaf development in Bryophyllum calycinum. Amer.J.Bot. 21: 467-484. 


\section{Agradecimientos}

Deseo dejar constancia de mi agradecimiento a las siguientes instituciones y personas:

Facultad de Ciencias Agrarias de la UNNE, en cuyo departamento de Botánica y Ecología realicé el trabajo.

CONICET, por haber desarrollado gran parte del trabajo mientras gozaba de una beca de perfeccionamiento.

Dra. Carmen L. Cristóbal, quien me brindó su conocimiento de la taxonomía y morfología del género. Tuvo además la gentileza de leer críticamente el manuscrito, asesorándome en la corrección del mismo.

Ing. Antonio Krapovickas, quien me dio útiles consejos en la elaboración del manuscrito.

Ing. Carlos Chifa, quien colaboró eficazmente en la preparación de los "slides" microscópicos.

Personal del Departamento de Botánica y Ecología, que de una u otra forma me prestó colaboración.

\section{Summary}

This paper is the study of the minor foliar venation of 119 species of Byttneria genus. There are many published papers about minor venation, but very few consider a big number of species of the same genus. Apparently there is no data about Byttneria. However, the paper provides a historic account on dicots foliar minor venation.

The analisis was done fundamentally on cleared adult foliage leaves, although leaf transections were utilized too.

The following elements were taken into account: areoles shape and size; veinlets frequence, number and branching; bundle sheath structure; foliar sclerenchyma composition and topography; bundle sheath extensions; occurrence and type of cristals.

There are two types of minor venation in Byttneria, named anisodictious and isodictious respectively. They are distinguished by the shape and size of areoles, and the frequence, number and branching of veinlets.

Each type of minor venation is divided into four groups. according to the structure of the bundle sheath (parenchymatous, differenciated, intermediate) and the topography of the foliar sclerenchyma (mononeural, oligoneural, polineural, holoneural).

The minor venation is analized in relation with the taxonomy of the genus. 
The species of Byttneria section show the same pattern: they have anisodictious venation with parenchymatous bundle sheath and holoneural sclerenchyma. Furthermore this section has certain exclusive characters as the possession of uniapertured nectaries, which contribute to separate it from the other sections.

Vahihara is the section which has the greatest variability. Isodictious minor venation is present solely in a group of species of this section, as well as the differenciated bundle sheath.

Urticifolia section has anisodictious minor venation, but offers extreme characters among its species with regard to the bundle sheath and foliar sclerenchyma.

The study of the features which compose the minor venation in Byttneria led to the following observations: 1) anisodictious minor venation appears in all the sections of the genus while isodictious minor venation appears only in 35 of the 60 species of Vahihara. 2) Parenchymatous bundle sheath is common to all sections whereas the differenciated bundle sheath is present merely in a certain group of Vahihara. 3) The amount of sclerenchyma is quite variable, although a great number of species have holoneural sclerenchyma and very few species have mononeural sclerenchyma.

According to these observations, the anisodictious venation pattern, with parenchymatous bundle sheath and oligoneural sclerenchyma is considered the most primitive of the genus (group 2). Starting from this pattern, 4 trends of specialization can be traced. The first leads to the pattern of group 1, through simplification of foliar sclerenchyma; the second leads to the pattern of subgroup 4 , by the increase of sclerenchyma; the third, to the pattern of subgroup $4 \mathrm{a}$, with the addition of a specialized bundle sheath. The last trend leads to the isodictious pattern of minor venation through a diminution of the areoles size and veinlets number and branching. This trend shows different levels of organization according to the bundle sheath type and sclerenchyma. 
Lámina 4. Venación menor anisodictia (A-E) e isodictia (F-J). Fig. A, B.Ostenii (Hassler 12145) G.2, x 32,5; Fig. B, B.glabrescens (Ellenberg 1321) G. 2, x 80; Fig. C, B.sagittifolia (Mattos 9641) G.4, x 32,5; Fig. D, B.Asplundii (Ferreyra 10882) G.4a, X 80; Fig. E, B.australis (Ule 1001) G.4a, x 32,5; Fig.F, B.echinata (Thorel s/n) G.6a. x 32,5; Fig. G, B.grandifolia (Lau 261) G.6b, x 32,5; Fig. H, B.celebica (Warburg`s/n) G.7, x 32,5; Fig. I, B.sambiranensis (Decary 1075) G.7a, x 80; Fig. J, B.uaupensis (Smith 2863) G.7b, x 80. 

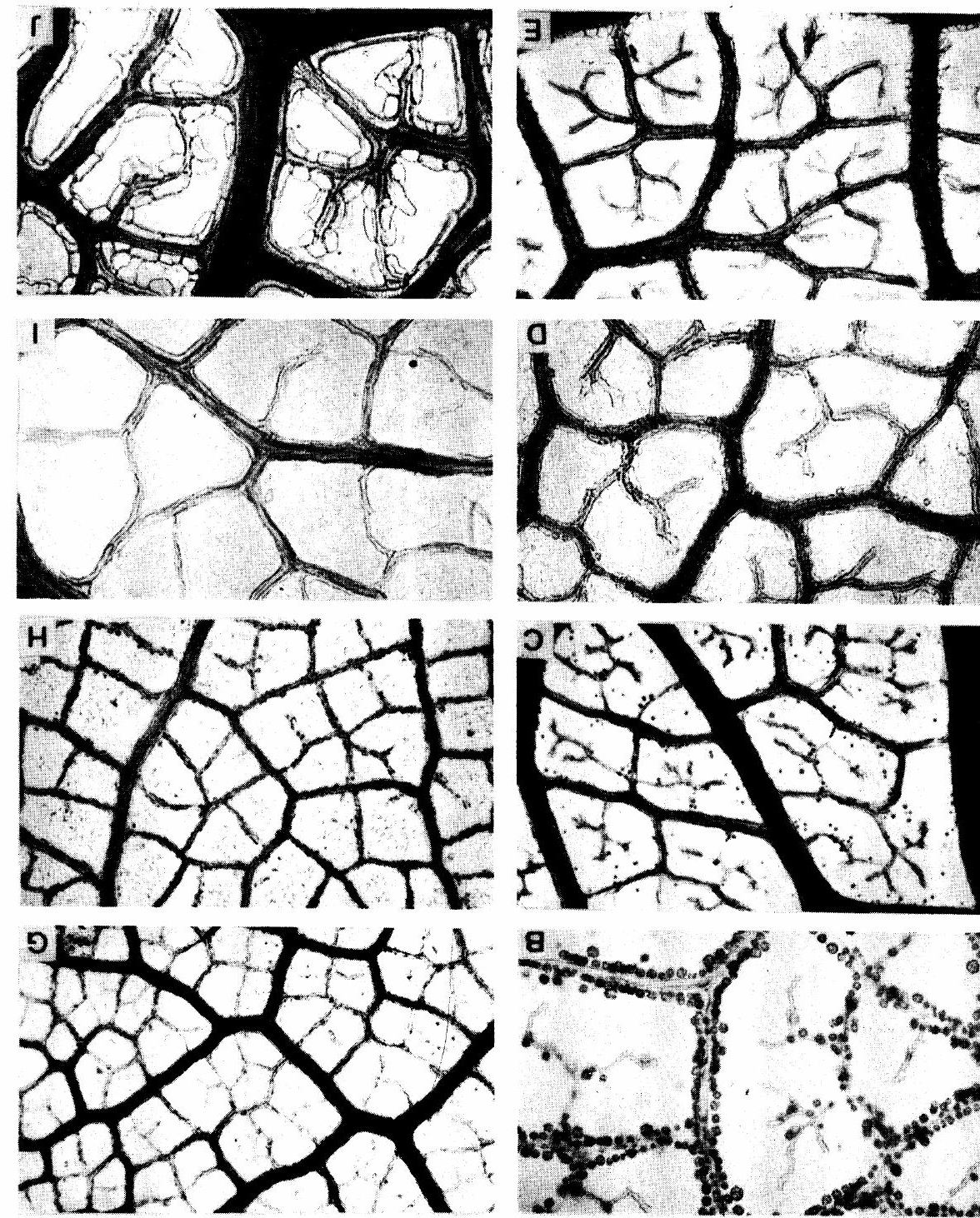

a.

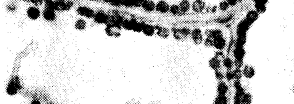

4.

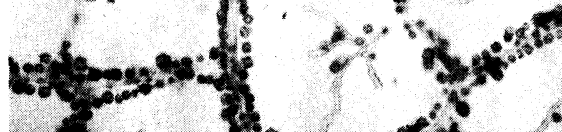
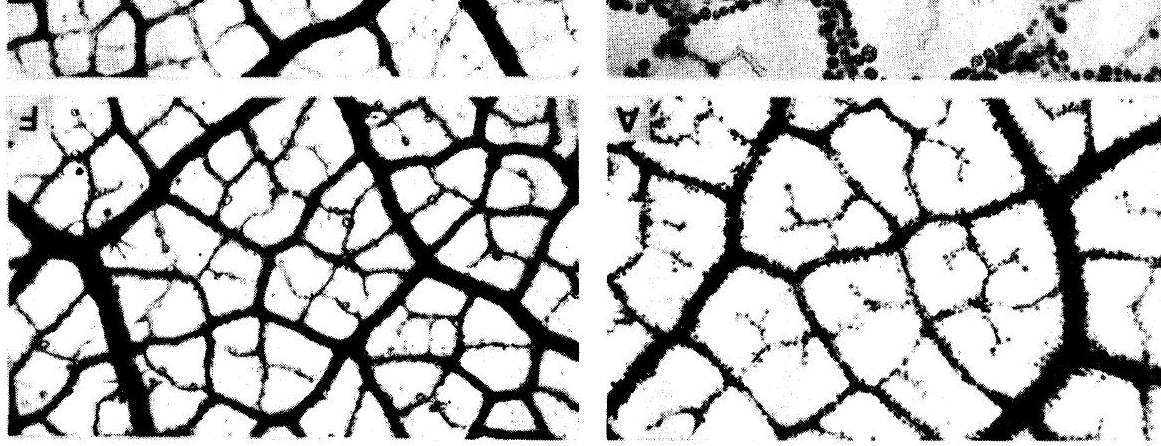
Lámina 5. Tipos de vaina y vénulas. Fig.A, Vaina diferenciada (B.uaupensis, Smith 2863) $\mathrm{x}$ 250; Fig.B, vaina intermedia (B.echinata, Thorel $s / n$ ) $\times 125$; Fig.C, vaina parenquimática (B.pilosa, Poilane 23365) x 125; Fig.D, venillas formadas por células de la vaina (B.Piresii, Rodriguez 79) x 250; Fig.E, vénulas con cristales en la vaina (B.microphylla, Howard 8635) x 170; Fig.F, vénulas robustas, bifurcadas (B.sagittifolia, Mattos 9641) x 175; Fig. G,vénula acompañada por células esclerenquimáticas (B.implacabilis, Krap. et al. 23074) x 180; Fig.H, vénula simple, con vaina intermedia (B.divaricata, Smith 2366 ) x 190; Fig.I, vénula ramificada, con elementos dilatados en los extremos (B.cordifolia, Sagot 925) x 190; Fig.J, B.urosepala (Sandemann 4467) con esclerénquima holoneural estrictamente, x 32,5; Fig.K, id, vénula acompañada por braquiesclereidas x 190 . 

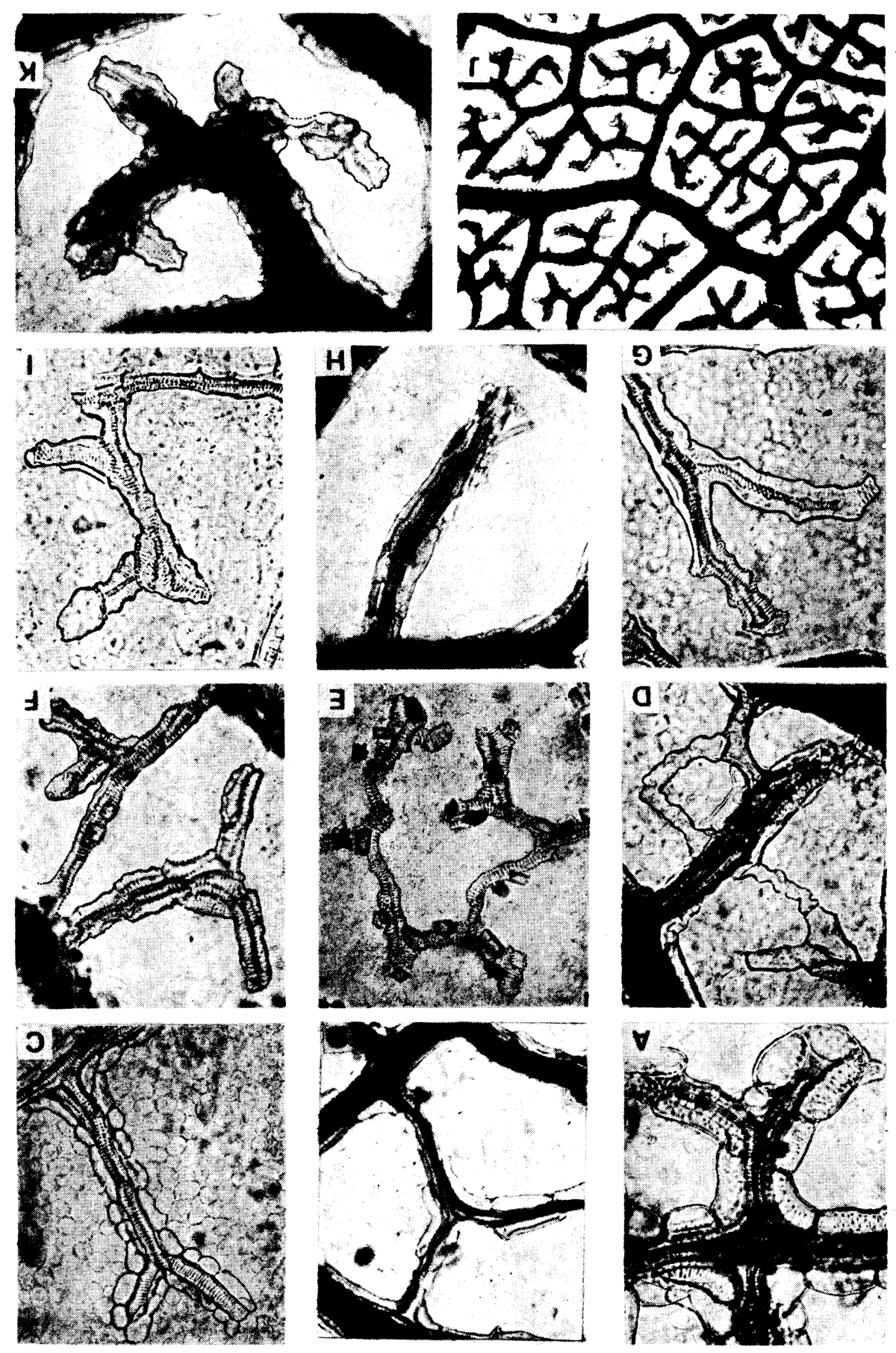
Se terminó de imprimir el día 18 de Abril de 1977, en la Dirección de Impresiones de la Universidad Nacional del Nordeste, Resistencia, Chaco, Argentina. 